\title{
Simultaneous Targeting Tumor Cells and Cancer-Associated Fibroblasts with a Paclitaxel-Hyaluronan Bioconjugate: in vitro Evaluation in Non-Melanoma Skin Cancer
}

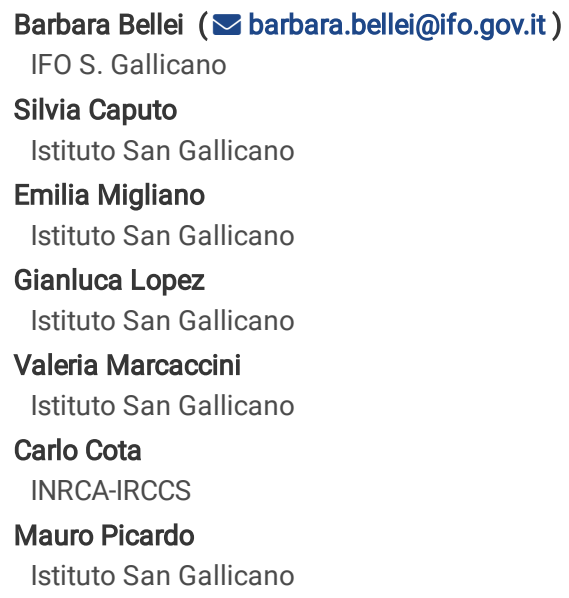

Version of Record: A version of this preprint was published at Biomedicines on May 24th, 2021. See the published version at https://doi.org/10.3390/biomedicines9060597. 


\section{Abstract}

Background: Cancers are complex organs which encompass not only the tumor cells but also cells within the surrounding stroma. Such cells, mainly cancer associated fibroblasts (CAFs) and immune infiltrating cells, facilitate many aspects of cancer development providing a structural and supportive framework rich of bioactive compounds. So far, there are emerging studies proposing the combination of conventional anti-cancer therapy, directed against neoplastic cells, to molecules targeting tumor microenviroment.

Methods: The study was designed to evaluated the pharmacological properties of the anti-tumor agent paclitaxel conjugated to hyaluronic acid (HA) on nonmelanoma skin cancer (NMSC) and on the surronding dermal fibroblasts. This molecule, named Oncofid-P20 (Onco-P20), targets preferentially cells expressing high level of CD44, the natural ligand of HA.

Results: Consistent with paclitaxel's mechanism of action involving interferences with the normal breackdown of microtubules during cell division, highly sensible carcinoma cells underwent rapidly to apoptotic cell death. Interestingly, less sensible cells such as dermal fibroblasts resisted to the Onco-P20 treatment and experirenced a senescent-like status characterized by morphological change, decreaded proliferation, and significant modification of the gene espression profile. Onco-P20-treated fibroblasts lowered growth factors production, down-modulate Wnt signal pathway and acquired a pro-inflammatory profile. Independently to the direct exposure to taxol, in presence of Onco-P20-treated fibroblasts or their conditioned medium, carcinoma cells reduced the proliferation rate. Similar to NHF, fibroblasts isolated from skin cancer tumor lesion or from tissue adjacent to the tumor acquired an anti-neoplastic activity under Oncofid-P20 treatment.

Conclusion: Collectively, our data demonstrated that Onco-P20, exerting both a direct and a NHF-mediated indirect paracrine effect on carcinoma cells, is a good candidate for an innovative therapy alternative to surgery for treatment of NMSC.

\section{Background}

Keratinocytes-derived non-melanoma skin cancer (NMSC), predominantly basal and squamous cell carcinoma, represents the most frequent malignant tumor worldwide [1]. Although they rarely metastasized, their locally aggressive invasion frequently mutilates patients. New results from investigation indicate the importance of tumor microenvironment on the biological properties of tumor, such as the aggressive growth and local recurrence. During malignant transformation, cancer cells acquire invasive properties, violate the basement membrane and invade the underlying dermis. Consequently, dermal stroma and epidermal cancer cells establish unusual heterotipic cell-cell contact and a dynamic cross-talk that leads to alterations of the host tissue [2, 3]. The parenchymal injury associated with a nascent and growing tumor constantly activated stromal cells driving the acquisition of cancer associated phenotype, that neither spontaneously revert to a normal phenotype nor undergoes cell death [4]. A particular feature of cancer stroma is the increased number of mesenchymal or fibroblastic cell type, pathologically activated referred as cancer associated fibroblast (CAFs). CAFs are embedded within an extracellular matrix (ECM) profoundly remodeled compared to the physiological one and rich of immune cell infiltrates and blood/lymphatic vessels. The ECM not only provides structural support for the cells but also participate to biochemical signal transduction through the binding of angiogenic and growth factors whose availability depends also on ECM remodeling [5-7]. CAFs are characterized by a distinct activated phenotype and by expression of a variety of markers, such

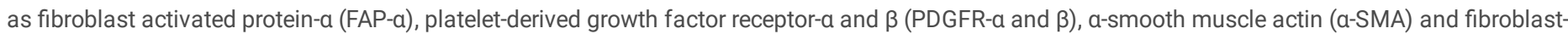
specific protein-1 (FSP1) [8-11]. CAFs in cancer tissue are morphologically similar to myofibroblasts, which are large spindle-shaped cells activated during the wound healing process and found in sites of chronic inflammation [12]. Based on similarity between tumor initiation and wound inflammation linked to myofibroblasts activation tumor has been defined as "wound that never heal" [13]. This notion implies the reversibility of fibroblasts activation and the possibility to target CAFs for cancer therapy [14]. Interestingly, not only fibroblasts within or directly in contact to tumor, but also those from cancer free tissue adjacent to tumor exhibit CAF phenotype [15]. This phenomenon could be explained by the intense release of bioactive molecules by tumor tissue and the consequent bi-directional dynamic cross-talk among cancer cells and surrounding cells. It has been suggested that the high secretory phenotype of CAFs play a key role in tumor progression, but increasing data also argue for their antitumor actions [16, 17]. In mouse model, reduced stromal content accelerates tumor growth and angiogenesis and full depletion of CAFs induces immunosuppression $[18,19]$. The capacity to sustain cancer depends largely by altered secretome, augmented pro-mitogenic peptide, regulation of inflammation and ECM whereas the capacity to inhibit cancer is supposed to predominantly depends on the interaction with the immune system. An increased production of a vast repertoire of growth factors has been reported overlapping amongst distinct tumor types including NMSC [4, 20-23]. Among these, VEGF, PDGFs, EGF, FGFs, and Wnts drive tumor growth and vasculature [24]. CAFs also secrete cytokines and chemokines that recruit and modulate the function of immune cells in the tumor microenvironment $[7,25]$. The peculiarity of the inflammation associated to tumorigenesis processes demonstrates chronic, non-resolving characteristics [25]. However, similar to mesenchymal cells, inflammatory cells operate in conflicting modalities: both tumor-antagonizing and tumor-promoting [26]. The balance between pro-inflammatory and anti-inflammatory response is deeply implicated in patient's prognosis $[27,28]$. It is not fully clear if the dual nature of cancer microenvironment reflects the contemporary presence of heterogenic populations or if differences reside in disease evolution. Thus, since CAFs co-evolve with genetically altered tumorigenic cells it is possible that an early anti-tumor phenotype is replaced by a pro-tumorigenic one during disease progression. In line with the idea that CAFs co-evolve with tumor cells, it has been demonstrated that normal dermal fibroblasts could be "educated" to assume CAFs gene signature by tumorigenic cells both in vivo and in vitro [29]. On the other hand, in the skin, chronic and long-term exposure to UV radiation, the major environmental risk factor for skin cancer [30], occurs on whole tissue impacting on pre-cancerogenous and resident stromal cells at the same time. Thus, differentially to internal organs, skin fibroblasts undergoes to a continuous extrinsic stimulation. Therefore, in the skin, alteration in the stroma can precede (or act independently) to epithelial cell alterations moving as a driver of the tumorigenic process. Thus, activated fibroblasts may play a relevant role in both initiating and progression of skin carcinogenesis. Consequently, in order to control cancer, we need to focus not only on the malignant cancer cells, but also on the benign microenvironment. In this study, we investigated the effect of the anti-tumor agent paclitaxel (PTX) conjugated to hyaluronic acid (HA), the CD44 ligand, a molecule named Oncofid-P20 (Onco-P20) on skin carcinoma cells, dermal fibroblasts and CAFs. PTX, a microtubule-targeting drug, enhances the polymerization of tubulin and also interacts directly with microtubules stabilizing them against depolymerization and enabling cells to form a normal mitotic apparatus [31]. Penetration-enhancing strategies including liposomes,

Page 2/20 
nanoparticles, implants and albumin-bound PTX have been proposed to bypass the poor water solubility of taxols. Improved skin penetration is desirable due to the proved efficacy of PTX against melanoma and non-melanoma skin cancer [32-34]. HA-conjugate is a highly biocompatible strategy to increase bioavailability and pharmacokinetic of active molecules especially in tissue presenting high hyaluronan receptor density such as the skin. Moreover, in many cancers of epithelial origin has been observed the up-regulation of CD44 [35]. In addition, CD44 is abundantly expressed by CAFs particularly in the hypoxic contest [36]. It has been previously demonstrated that dermal fibroblasts primed with PTX are capable release functional active PTX reducing melanoma cells [37]. In line with this set of preliminary data, using Onco-P20, we analyzed the impact of PTX treatment in the context of NMSC. We demonstrated, Onco-P20 combines in a single molecule two synergic activities: direct anti-tumor efficacy on keratinocyte-derived skin cancer and an indirect anti-tumor activity dependent on the modulation of CAFs secretory profile. Based on HA-CD44 interaction, Onco-P20 targets fibroblasts more efficiently than free PTX representing a valid alternative to surgery for treatment of non-melanoma skin carcinoma.

\section{Methods}

Ethic statement. The Declaration of Helsinki Principles was followed and patients gave written informed consent to collect samples of human material for research. Further, the Institutional Research Ethics Committee (Istituti Regina Elena e San Gallicano) approved all research activities involving human subjects.

Preparation of hyaluronan-paclitaxel bioconjugate. The preparation of HA-paclitaxel bioconjugate (Oncofid-P20) with 20\% w/w of paclitaxel (taxol) loading has been previously described [38]. Oncofid-P20 and paclitaxel (donated by Fidia Farmaceutici, Abano Terme, Italy) were diluted with DMSO. Solutions were further diluted at each experimental day in order to achieve a $0.05 \%$ final DMSO concentration.

Cell cultures. Primary cultures of normal human keratinocytes (NHK) and fibroblasts (NHF) were isolated from human skin fragments obtained from surgery. NHK were maintained in M154 medium with Human Keratinocytes Growth Supplement (HKGS) supplements (Cascade Biologics Inc., Portland, OR USA), Ca ${ }^{2+}$ $(0.07 \mathrm{mM})$ and antibiotics; NHF were maintained in DMEM (EuroClone S.p.A., Milan Italy) supplemented with $10 \%$ FBS and antibiotics (Hyclone Laboratories, South Logan, UT, USA). Cancer-associated fibroblasts (lesional and perilesional) and paired normal fibroblasts were isolated from 5 tumor samples of patients, 4 SCC and 2 BBC using the same methods. Carcinoma cells were washed three times with PBS, then minced into approximately $1-2$ mm² sized pieces and digested using $5 \mathrm{~mL}$ of a $0.1 \%$ trypsin solution (Gibco, CA, USA). After variable digestion time (2-6 hours), the homogenate was collected and passed through a 70 $\mu \mathrm{m}$ strainer and cultured in M154 plus HKGS. A431 and SCC1300-UC cell lines were cultured in DMEM containing $10 \%$ FBS or in M154 plus supplements where indicated. Images were recorded using an Axiovert 25 inverted microscope (Carl Zeiss, Oberkochen, Germany) and a Power Shot G5 digital camera (Canon, Inc., Tokyo, Japan).

Proliferation assays. Briefly, $2.5 \times 10^{4}$ keratinocyte or $0.8 \times 10^{4}$ fibroblasts were seeded into the 24 -well plates for 24 hours to adhere. Then, growth medium was changed with fresh medium containing treatments (or not for control cells) at the appropriate concentrations. Culture medium and drugs were refreshed twice a week. At the experimental end point cells were incubated with 3-(4,5 dimethylthiazol)-2,5-diphenyl tetrazolium bromide (MTT) for 2 hours. After this time, the medium was removed and the resulting crystals were solubilized in DMSO. The absorbance was measured at $570 \mathrm{~nm}$ with a reference wavelength of $690 \mathrm{~nm}$. Absorbance readings were subtracted from the value of blank wells, and results were calculated as a percentage of absorbance respect to control samples. Experiments were performed in duplicates.

Preparation of CAF conditioned medium (CM). Human skin CAFs were plated into a $10 \mathrm{~cm}^{2}$ dish and a conventional culture was carried out for 24 hours before Onco-P20 treatment. Subsequently, fresh DMEM + 10\% FBS containing treatment (or not for control cells) was replaced twice a week. After 2 weeks and an additional $48 \mathrm{~h}$ period without treatment, medium was replaced with DMEM without FBS before CM harvesting. The supernatant was collected, centrifuged at 1,000 rpm, filtered with a $0.22-\mu \mathrm{m}$ membrane for sterilization. $\mathrm{CM}$ of untreated fibroblasts was used as control medium. Experiments were performed in duplicates.

Trans-well co-culture. Briefly, $12 \mathrm{~mm}$ trans-well with $3.0 \mathrm{~mm}$ pore membrane insert were used with CAFs and cancers cells alternatively in the lower or upper compartment. $2.0 \times 10^{4}$ fibroblasts per well were seeded in the lower compartment or alternatively $0.8 \times 10^{4}$ fibroblasts were seeded in upper compartment and incubated at $37^{\circ} \mathrm{C} 5 \% \mathrm{CO} 2$ overnight. Then, fresh DMEM + 10\% FBS containing treatment (or not) was replaced twice a week. After 2 weeks DMEM was replaced with $\mathrm{M} 154$ without treatment. After 48 hours, trans-well inserts containing $2.0 \times 10^{4}$ carcinoma cells were added. Otherwise, $2.0 \times 10^{4}$ carcinoma cells were seeded in lower compartment before insert addition. After 96 hours MTT assay was developed. Experiments were performed in duplicates.

Western blot analysis: Cell extracts were prepared with RIPA buffer containing proteases and phosphatases inhibitors. Proteins were separated on SDSpolyacrylamide gels, transferred to nitrocellulose membranes and then treated with the following primary antibodies: mouse monoclonal anti-b-catenin, anticyclinE (1:1000) (Santa Cruz Biotechnology Inc., Santa Cruz, CA, USA), anti-bFGF (1:500) (Upstate Biotechnology, Inc., USA), anti-p53, anti-cyclinD1 (1:1000) (Dako, Agilent Technology Italia, Milan, Italy), rabbit polyclonal anti-p21, anti-p27 (1:500), anti-cyclinB1 (1:1000) (Cell Signaling Biotechnology), and goat antiKGF (1:200), (Santa Cruz Biotechnology) antibodies. Anti- $\beta$-actin mouse monoclonal antibody (1:5000) (Sigma Aldrich, Merck KGaA, Darmstadt, Germany) was used to normalize protein content. Horseradish peroxide-conjugated goat anti-mouse, goat anti-rabbit or bovine anti-goat secondary antibody complexes were detected by chemiluminescence (Cell Signalling Technology, MA, USA). Imaging and densitometric analysis were performed with UVITEC Mini HD9 acquisition system (Alliance UVItec Ldt, Cambridge, UK).

Elisa assay. Growth factors and bioactive molecules concentration released in culture medium were measured after 2 weeks treatment using commercially available enzyme-linked immunosorbent assay (ELISA) kits according with manufacturer's instructions: HGF (Cusabio Technology LLC, Baltimore, MD, USA), IGFBP4 and 6 (Aviva Systems, Biology, CA, USA) and VEGF-A (eBioscience, Inc. San Diego, CA, USA). Cells were incubated for 48 hours with DMEM without FBS before medium collection. Results were normalized against protein concentration. 
Immunofluorescence analysis. Cells on coverslips were fixed with $4 \%$ paraformaldehyde for 20 minutes at room temperature followed by $0.1 \%$ Triton X-100 to allow cell permeabilization. Cells were then incubated with anti-PML (1:500), for 1 hour. Primary antibodies were visualized using anti-rabbit IgG Alexa Fluor 488 (BD Bioscences, Milan, Italy). Nuclei were visualized with 4',6'-diamino-2-phenylindole (DAPI). Fluorescence signals were recorded using a CCD camera (Zeiss, Oberkochen, Germany).

Flow cytometry analysis. Cell death and apoptosis were analyzed by annexin-V FITC/propidium iodide (PI) double staining method after 48 hours of treatment. Cells were harvested by trypsinization, suspended in the staining buffer ( $10 \mathrm{~mm} \mathrm{HEPES} \mathrm{/} \mathrm{NaOH,} \mathrm{pH} 7.4,140 \mathrm{~mm} \mathrm{NaCl}, 2.5 \mathrm{~mm} \mathrm{CaCl}$ ), stained with FITC-labeled annexin V and PI for 15 min at RT in the dark and then kept on ice until be analyzed. For cell cycle distribution, after cells harvesting by trypsinization, cells were fixed in cold $70 \%$ ethanol for 10 minutes and then stained with propidium iodide $(\mathrm{PI})$ solution $(1 \mu \mathrm{g} / \mu \mathrm{L} \mathrm{PI}$ and $0.125 \% \mathrm{RNaseA}$; Sigma Aldrich, St. Louis, MO) at room temperature for 15 minutes. 20,000/sample cells were analyzed using a FACS Calibur instrument (BD) equipped with a 488nm argon ion laser. The percentage of cells in each phase of the cell cycle was determined using FlowJo software v8.0. The amount of membrane bound CD44 was measured incubating unfixed cells with a CD44-PE antibody (BD Biosciences) before cells wash and cytofluorimetric analysis.

Cytokines protein array. The expression of 20 human cytokines was analyzed using a commercially available antibody array system (RayBio ${ }^{\circledR}$ C-Series Human Inflammation Array C1 Map, RayBiotech, Inc) that uses membrane-bound cytokine-specific antibodies to capture cytokines in biological fluids. The procedure was performed as per the manufacturer's instructions. Cells were seeded in 10-cm culture dishes and treated (or not) with Onco-P20 $0.15 \mathrm{mg} / \mathrm{mL}$ for $2 \mathrm{weeks}$. After removing drug cells were maintained in serum-free medium for 48 hours. The cytokine array membranes were blocked in $2 \mathrm{ml} 1 \times$ blocking buffer for 30 min at room temperature (RT) and then were incubated with $1 \mathrm{ml}$ of conditioned medium at $4^{\circ} \mathrm{C}$ overnight. The medium was then decanted from each container, and the membranes were washed three times with $2 \mathrm{ml} 1 \times$ wash buffer l, followed by two washes with $2 \mathrm{ml} 1 \times$ wash buffer II at room temperature. Next, the membranes were incubated in biotin-conjugated primary antibodies for 2 hours at RT and then washed as described above before incubation in 1:1000-diluted horseradish peroxidase-conjugated streptavidin for 2 hours. The membranes were then washed thoroughly and incubated with a chemiluminescent ECL substrate at RT for 5 min. Imaging and densitometric analysis were performed with UVITEC Mini HD9 acquisition system (Alliance UVItec Ldt, Cambridge, UK).

Statistical Analysis: Results in the figures are representative of several experiments we performed with at least five cell lines from different donors. Quantitative data were reported as mean \pm standard deviation (SD). Student $t$-test was used to assess statistical significance with thresholds of * $\mathrm{p} \leq 0.05$ and ${ }^{*} \mathrm{p} \leq 0.01$.

\section{Result}

\section{Effect of Oncofid-P20 treatment on cell proliferation and viability}

A431 human squamous carcinoma cells, a commonly model used for studies of skin cancer and normal keratinocytes (NHK) from healthy subjects were treated with a broad panel of Onco-P20 concentration $(0.05-1 \mu \mathrm{g} / \mathrm{mL})$ for 72 hours before MTT assay and cells count. MTT assay showed a strong reduction of $\mathrm{NAD}(\mathrm{P}) \mathrm{H}$-dependent cellular mitochondrial activity in Onco-P20-treated carcinoma cell cultures that correlated to a significant reduction in the number of cancer cell at all the concentrations tested (Fig.1a and b). In contrast, at the experimental end point in NHK Onco-P20 treatment mildly impacted on metabolic function and on the number of cells resulted modestly reduced (Fig. $1 \mathrm{c}$ and d). Hyaluronic acid, alone did nor exerted any significant modification of cell viability and proliferation indicating that this portion of the molecule is not implicated in the biological activity observed. Since in addition to cell count, microscopic observation of cell cultures highlighted marked differences comparing normal and tumor cells (Fig. 1e), we additionally evaluated cell cycle distribution demonstrating G2/M accumulation in both cell types and extensive cell death only in cancer cells (Fig. 1f). Significant increase in the number of apoptotic cells was confirmed by AnnexinV/PI staining proving the selective cytotoxic effect on tumor cells (Fig. 1g). Thus, while in carcinoma cultures metabolic activity measurement and the number of apoptotic cells correlated indicating that cell death is the main mechanism of Onco-P20 function, in normal keratinocyte, all the concentrations tested, the treatment reduced the metabolic activity without affecting cell viability. However, high doses of OncoP20 $(>0.25 \mu \mathrm{g} / \mathrm{mL})$ impacted on keratinocyte proliferation capability as evidenced by cell accumulation in G2/M cell cycle phases.

Since established cell lines maintained in culture for a long period frequently present evidence of deviations from the phenotype of the originating tumor, we used a collection of specimens from patients well characterized for disease stage and follow up to isolate low passage tumor cell lines and patient-matched normal keratinocytes cultures. In this case, cytotoxic effect against short term carcinoma cell cultures showed an overall lighter intensity compared to A431 cells and the MTT assay, that does not discriminate between cytotoxic and cytostatic effect, displayed modest difference between normal and carcinoma cells (Fig. 2a and b). By contrast, AnnexinV/PI staining confirmed that Onco-P20 preferentially reduced viability of neoplastic cells (Fig. 2b). Since A431 cell cultures and fresh isolated carcinoma cells were cultured in non-overlapping growth condition (DMEM supplemented with FBS and chemically-defined medium M154 supplemented with HKGS respectively; see material and method section), we addressed the question if the observed differences could be attributed to culture medium composition or to distinctive biological properties. In this case, we used A431 and SCC1300-UC, one of the low passage SCC cell lines isolated in our laboratory capable to proliferate both in defined media (M154 plus HKGS) as well as in high calcium FBS-containing DMEM medium, to evaluate the impact of cell medium composition on Onco-P20 treatment. As shown in Suppl. Fig. 1, the sensibility to Onco-P20 treatment resulted attenuated in M154 defined medium compared to DMEM plus serum (Fig. S1a) and inversely correlated to the proliferation rate (Fig. S1b). In fact, cell culture composition influenced cell growth demonstrating a significant slower growth curve kinetic in chemically defined medium that correlated with lower pharmacological activity. However, responsiveness to Onco-P20 is also an intrinsic characteristic of different cell lines related to the CD44 level of expression that is not necessarily overexpressed in skin carcinoma compared to normal cells [39]. In fact, FACS analysis confirmed that patient-derived carcinoma specimens present a moderate level of CD44 expression comprised between those of normal cells and one of A431 cells (Fig. 3a). The low presence of CD44 on the membrane could partially explain the higher response of A431 that could be still appreciated using identical growth condition (Fig. S1a). Accordingly, with the idea that the relative abundance of CD44 is not particularly elevated in the keratinocyte lineage, hyaluronan-conjugate formulation failed to demonstrate any significant gain of 
function in comparison to conventional free paclitaxel (Fig. S2).

CD44 overexpressing cells comprise not only tumor cells and cancer stem cells but also CAFs [40-42]. Strongly CD44-positive CAFs are particularly frequent in tumor hypoxic areas [36]. Since also dermal fibroblasts physiologically express high level of this receptor (Fig.3b) we evaluated the effect of Onco-P20 on normal human fibroblasts (NHF). For this purpose, and in line with patient's characteristics, we used adult fibroblasts isolated from photo-exposed area of geriatric donors. NHF treated with Onco-P20 $(0.05-1.0 \mu \mathrm{g} / \mathrm{mL})$ for 72 hours displayed attenuation of mitochondrial activity and a significant abatement in cellular proliferation compared to control cells (Fig.4a and b). Similar to normal keratinocytes, fibroblasts did not show acute cytotoxicity as measured by AnnexinV/PI double staining (Fig. 4c). Cell cycle analysis evidenced a marked accumulation in the G2/M phase (Fig. 4d). In addition, evidences of cell hypertrophy (a large cell morphology), a universal marker of in vitro cell senescence [43] appeared at days 3-5 (Fig.4e). Increase expression of p53 and p21, as well as, the presence of several promyelocytic leukemia protein (PML)-nuclear bodies, typical nuclear matrix structures implicated in the induction of the senescence process [44], confirmed diminished proliferative propensity of Onco-P20-treated cells (Fig. 3f and g). In contrast to p21, another important cell cycle checkpoint CDK inhibitor, p27 resulted decreased. Cyclin E, that is required and rate liming for S phase entry, is lightly downregulated. We further analyzed the protein level of cyclins in Oncofid-P20-treated cells. The level of cyclin D1 which promotes progression through G1/S phases was elevated, while cyclin B1, promoting G2/M transition, was barely present [45, 46]. According with previous studies $[47,48]$ the cyclins profile was consistent with G2-arrest. However, fibroblasts seem to be long-term arrested rather than irreversible senescence since after treatment removal cells resumed proliferation even in case of prolonged exposure to Onco-P20 (Fig. S4).

Finally, Onco-P20 activity was compared with that of equal amount of free paclitaxel. Following 72 hours drugs exposure, unconjugated paclitaxel exhibited a significant lower effect on NHF (Fig.5a). Thus, due to high level of CD44 expression on the membrane surface of mesenchymal cells, Onco-P20 exerts a stronger pharmacological activity then free paclitaxel. Moreover, to simulate drug availability in the case of topical application on patient's skin, we exposed NHF to treatments (Onco-P20 or paclitaxel) for a defined short period (8 hours) before wash out and subsequent cell culture in drug-free medium. In this case, using the same end point of previous experiments we observed reduced proliferation exclusively in Onco-P20-treated cells, whereas paclitaxel failed to modified fibroblast proliferation (Fig.5b). By contrast, in carcinoma cells no differences were observed comparing Onco-P20 and paclitaxel using short period treatment (Fig. 5c). However, it is interesting to note that in this case both molecules exerted a mild effect suggesting or an augmented sensibility to taxol of carcinoma cells compared to fibroblasts or an accelerated trigger of drugs effect.

\section{Onco-P20 deeply modifies fibroblasts gene and protein expression profile}

Given that fibroblasts could impact keratinocytes homeostasis through diffusible molecules, we assessed the impact of Onco-P20 on the expression of secreted proteins involved in tumor progression. Under these circumstances, several growth factors were differentially expressed in Onco-P20-treated fibroblasts versus control samples (Table 1). Among these, HGF was strongly down-regulated both at mRNA and protein levels (Fig. 6a). Additionally, the high molecular weight of bFGF, frequently associated with a poor prognosis in various human cancer [49], was reduced by Onco-P20 (Fig. 6b), whereas its mRNA resulted unmodified. However, since high molecular weight isoforms of bFGF are associated to highly proliferative phenotype of fibroblast [50], it is possible that the observed difference reflects an autocrine control of cell growth. Similarly, KGF resulted decrease mostly at protein level. EGF transcript was near to the detection limit in most of the fibroblasts cultures and lightly reduced by the treatment. The IGF was unchanged whereas, members of insulin-like growth factor binding proteins (IGFBPs) superfamily, a group of secreted proteins capable to binding IGFs and to modulate the mitogenic, anti-apoptotic and metabolic actions of IGFs, were found strongly increased. In particular, IGFBP3, IGFBP4, IGFBP5, IGFBP6 and IGFBP7 mRNA were significantly up-modulated. Immunoenzymatic quantification of IGFBP4 and 6 confirmed gene expression analysis (Fig. 6a). Possible repression of neo-angiogenesis is supported by reduced expression of vascular endothelial growth factors (VEGF) at mRNA and protein level (Fig. 6b).

The Wnt/ $\beta$-catenin signaling pathway, known to be activated in CAFs [51, 52], resulted down-modulated in Onco-P20-treated fibroblasts as demonstrated by decreased of $\beta$-catenin, the pivotal molecule of the Wnt signaling pathway (Fig. 6a). Accordingly, the expression of some negative regulators of the pathway, Wnt5a, DKK1 and SFRP2, were increased suggesting an autocrine mechanism of Wnt signaling regulation. By contrast, TGFb expression resulted unchanged. Among CAF's markers, PDGFa and b were reduced whereas the expression of FAP1 and aSMA resulted increased and unmodified respectively. Strong increase of IL1a, IL1b, IL6 and IL8 argues for the activation of inflammatory pathways. To further investigate signal transduction pathways involved in cancerfibroblasts cross-talk, we investigated a wide range of cytokines and chemokines using gene expression array cards and an antibody membrane array. Among the 93 mRNA studied, 38 were in most or all the sample undetectable and were discarded from the analysis, 13 resulted unmodified by the treatment, 2 lightly decreased and 40 enhanced (>1.5 fold-increase). Of these highly expressed transcripts 17 reached the statistical significance ( $\leq \leq 0.05$ or $p \leq 0.01)$ (Table 2 ). Most of the protein up-regulated, including KLK14 and members of MAP kinase family, such as MAPK8 (JNK1) and MAPK14 (p38a), are implicated in the IL1 pathway. The expression of IL1R1 in tumor microenvironment, the main receptor of IL1a and b, due to the interconnection with NF-KB and MAP kinase pathways plays contrasting roles in different tumor stage [53]. Sustained PTGS2 (cox-2) expression confirmed pro-inflammatory profile of NHF Onco-P20induced phenotype. Annexin1A (ANXA1), increased by Onco-P20, has been proposed as a tumor suppressor in head and neck squamous cell carcinoma [54]. However, in prostatic cancer, ANXA1 exacerbated expression of this marker has been correlated to high amount of cancer stem cells [55]. Interestingly, CD40 an antigen frequently loss by basal and squamous cell carcinoma during tumor escape from activated T cells, was augmented by Onco-P20 treatment. Intercellular adhesion molecule-1 (ICAM1, CD54), a receptor that support leukocytes accumulation in inflamed tissue, resulted strongly enhanced whereas vascular cell adhesion molecule-1 (VCAM), another mediator of leukocytes trafficking, was lightly increased. Additionally, high LTA4H that catalyzes the hydrolysis of epoxide LTA4 to LTB4, which mainly functions as a neutrophil, macrophage, and T lymphocyte chemoattractant, confirmed the inflammationenhancing effect of Onco-P20. The antibody array used to quantified secreted inflammatory factors confirmed a significant arise in IL6 and IL8 production whereas IL $1 \mathrm{a}$ and ILb appeared moderately increased at protein level. Additionally, the secretion of CCL11 (Eotaxin-1), a chemokine implicated in eosinophils recruitment [56], was up-regulated by Onco-P20 (Table 3). Lastly, CCL1, whose release by fibroblast has been linked to bladder cancer cells invasion [57], significantly diminished. 


\section{Secretome of Onco-P20-treated fibroblasts modulates carcinoma cells growth}

Cancer and stromal cells communicate mainly by a complex bidirectional cross-talk that evolve during disease progression and the diffusion of soluble factors through basement membrane. To study the effect of Onco-P20-induced fibroblast phenotype on cancer cells simulating the in vivo situation, we used two different experimental systems: fibroblast pre-treated conditioned medium (CM) and the trans-well permeable support (TW) to growth tumor and stromal cells on two different but connecting monolayer. Taking in consideration that previous studies evidenced that mesenchymal cells are capable to release into the microenvironment functional active paclitaxel for 24 hours [37], in both cases we replaced Onco-P20 containing medium with fresh starved medium 48 hours before collect $\mathrm{CM}$ or start co-culture experiments. In either way, due to the absence of paclitaxel and serum, cell proliferation depends exclusively by autocrine and paracrine activity of both cell populations. At the experimental end point (72 hours), both systems clearly demonstrated that carcinoma cells dose-dependently slowed the proliferation rate in presence of Onco-P20-pretreated fibroblasts o their CM (Fig.7a-and b). The anti-proliferative effects observed depends on the dose of drug used to treat NHFs and on the relative fibroblasts-carcinoma ratio as demonstrated by the stronger reduction of A431 cells growth in the trans-well upper (smaller) compartment compared to the lower one. Further, co-culture data were confirmed using a patient derived model assembled with NAF, CAF and carcinoma cells from the same donor (Fig.7c) or NAF, CAF and A431 cell line for cases presenting unsuccessful isolation of tumor cells in vitro (Fig.7d). Overall, data demonstrated that the sensibility to Onco-P20 of CAFs is similar to normal fibroblasts.

\section{Discussion}

Skin diseases represent a significant health burden. Although epithelial skin cancers rarely metastasize, they grow invasively and their removal often leads to severe functional and aesthetic impairments [58]. Therefore, there is a strong need for the development of cost effective and well tolerated therapies. The use of topical pharmacologic intervention aims to treat superficial form of NMSC decreasing the rate of disease progression and to offer an effective nonsurgical prospective. Increasing studies demonstrated that in tumors, the stroma is not simply a collection of enclosing cells without malignant function [7, 59]. CAFs have been indicated as a key component of the cross-talk between cancer cells and their microenvironment. A dichotomist role has been attributed to CAFs. It is generally accepted that CAFs stimulate cancer cell growth and metastatic behavior $[18,60]$. Substantially, cancer cells utilize the CAF-secreted growth factors to facilitate their own survival and proliferation. However, depletion of CAFs led to invasive, undifferentiated tumors with enhanced hypoxia, and cancer stem cells, with reduced animal survival $[18,19]$. Thus, based on the idea that fibroblasts have an exceptional phenotypic plasticity, including its secretory phenotype, it has been proposed that CAFs could be re-oriented to an anti-tumor phenotype for therapeutically purpose. However, to efficiently direct

CAFs activity against tumor we need to promote exclusively antineoplastic properties. Recent studies demonstrated that CAFs are important modulators of the anti-tumor immune response [61,62]. Consequently, among the potential approaches targeting the regulation of fibroblast-immune cells cross-talk represents and emerging strategy. Here, we demonstrated that Paclitaxel-Hyaluronan conjugate could target cancer cells and surrounding fibroblasts creating a synergism between direct and indirect anti-cancer effects. Previous studies demonstrated that Onco-P20 conjugate interacts with CD44, enters cells through a receptor mediated mechanism, and exerts a concentration-dependent inhibitory effect against tumor cells [38, 63, 64]. In preclinical studies, HA-taxol has demonstrated reduced toxicity, enhanced tumor accumulation, a greater anti-tumor efficacy compared to free taxol in ovarian and bladder carcinoma [63, 65]. However, in line with previous studies we observed that during the carcinogenic process, keratinocytes lightly increase the level of CD44 on the membrane and consequently Onco-P20 failed to demonstrate any significant advantage in the pharmacological activity compared to free paclitaxel in this cell type. Thus, we postulated that the modest augmented receptor-mediated uptake is balanced by smaller size and lipophilic nature of free paclitaxel that easily diffuses across cell membrane in vitro [66-68]. Although, the absence of any advantage in receptor-mediated uptake, the use of a hydrophilic HA backbone is still of interest in vivo to overcome the limited aqueous solubility of paclitaxel. Independently to the kinetic of drug internalization, tumor cells under tubulin polymerization/depolimerization anti-cancer agent treatment undertake the apoptotic cell death, whereas normal cells resist adopting a non-proliferative state $[69,70]$. The presence of functional p53 plays a crucial role in the level of cytotoxicity by paclitaxel. Cells lacking wild-type p53 respond through a p53independent apoptosis, whereas cells expressing active p53 resist paclitaxel toxicity by growth arrest [71, 72]. Consistently, we observed a divergent destiny comparing normal and transformed keratinocytes. NHK resist to paclitaxel exposure increasing G2/M arrest. In cells of mesenchymal origin, the switch to a quiescence state following paclitaxel exposure has been already described [73]. However, studies mainly focused on mesenchymal stem cells and on the possibility to use paclitaxel resistant cells as a reservoir of active compound (as a Trojan horse) for local-regional drug delivery [74]. Very recently, Coccè and co-workers, demonstrated that gingival mesenchymal stem cells treated with paclitaxel release vesicle containing an anti-cancer secretome in addition to free paclitaxel [75].

Here, we demonstrated that Onco-P20-treated dermal fibroblasts present a consistent reorganization of several intracellular signaling. Most of the detected markers are referred to the block of cell cycle progression leading to a stress-induced non-proliferating status resembling a senescent-like phenotype. The observed G2 phase accumulation is a reversible state that at least in vitro does not necessarily fully corresponds to senescence, since after taxol wash out cells re-started to proliferate. This is an important point in consideration of the impact of treatment on tissue integrity and its long-term persistence. In fact, rapidly replaced cells, such as keratinocytes are naturally protected to accumulation of dysfunctional cells, due to normal turnover by new differentiating cells whereas, dermal fibroblasts are long-lived elements capable of proliferation under appropriate stimuli [76, 77].

The presence of senescent cells in premalignant lesions in various mouse tumor models and human patients [78, 79] is consistent with cellular senescence acting as a brake to the development of cancer. Hence, tumor cells must bypass the mechanisms that impose cellular senescence response in order to proliferate $[14,80]$. Senescent-associated phenotype sensitizes surrounding cells to senesce. Thus, it is possible that cancer cells senescence, the first line of cancer protection, rapidly spread out to adjacent stromal cells. Accordingly, fibroblast senescence is a very early event in the carcinogenic process [81]. Whilst senescence acts as a tumor suppressor when activated in the epithelial compartment, the senescence of fibroblasts is frequently referred as a characteristic of CAFs suggesting that the associated secretome could play a role in cancer progression. In apparent contradiction to the concept that fibroblasts in the tumor contest resemble senescent fibroblasts, CAF is reported as a hyper activated state associated to an augmented proliferation rate [82-84]. Moreover, CAFs are considered similar to myofibroblasts activated after injury, a situation that promote mesenchymal cells expansion rather than proliferative arrest as in the case 
of Onco-P20 treated cells. In addition, reprogramming activated fibroblasts or CAFs back into their dormant state has been proposed strategy for impairing tumorigenesis [16]. Thus, even if Onco-P20-treated fibroblasts display some biomarkers of senescence the observed changes in gene expression do not fully

overlaps with those of senescence phenotype of CAFs. One of the detrimental aspect of CAFs is the over-production and secretion of growth factors which can induce proliferative signals within cancer cells. By contrast, dermal fibroblasts under continuous treatment with Onco-P20 decrease the production of some growth factors. Notably, we observed down-regulation of HGF and simultaneous increase of most of the IGFBPs that suggests a reduced bioavailability of IGF. Both HGF and IGF stimulate directly and indirectly (supporting angiogenesis) tumor growth [77, 85]. HGF facilitates transformed epithelial cells migration and protect cancer cells from chemotherapeutic agents [77, 86, 87]. Moreover, IGF1 and IGF2 mediate cancer cells resistance to paclitaxel in murine model [88] suggesting that lowered IGF biodisponibility could heightens chemotherapy. Interestingly, IGF1 diminishes in senescent and physiological aged dermal fibroblasts $[89,90]$ whereas it's production is augmented in CAFs [91] confirming that CAFs are not simply senescent fibroblasts. Also KGF, whose overexpression by fibroblasts enhances proliferation of basal keratinocytes and suppress epidermal cells terminal differentiation [92-94], decrease in presence of Onco-P20. Minor production of growth factors may represent an autocrine control of proliferation when cell cycle progression is not possible, a situation that in the contest of carcinogenesis could play an important role in paracrine regulation of tumor growth. Reduced fibroblasts mitogenic activity could also counteract the increased number of CAFs in the reactive stroma. This idea is supported by a very recent study reporting fewer stromal CAFs in pancreatic cancer patients after treatment with nanoparticles containing paclitaxel [95]. Wnt signaling deregulation in human SCCs has been evidenced not only in cancer cells but also in stromal fibroblasts [96], suggesting that Wht pathway might act in a paracrine fashion to promote skin carcinogenesis. Fibroblasts treated with Onco-P20 reduced the level of b-catenin expression and increased the production of soluble factors capable to diffuse similar Wnt pathway modulation to neighboring cells.

In line with the idea that when the cell cycle is blocked downstream, pro-inflammatory pathway is over-activated [97], the most prominent feature of Onco-P20growth arrested fibroblasts is a consistent pro-inflammatory secretory profile. The pro-inflammatory gene signature has been evidenced in early hyperplastic lesions as well as in end-stage squamous cell carcinomas [29]. Immuno-modulatory cytokines secreted by fibroblasts have a double edged sword effect in cancer biology. Some cytokines overexpressed in Onco-P20 treated fibroblasts influence the mobilization of local immune system playing a relevant role in defense against cancer $[98,99]$. For example, CCL11 is implicated in eosinophils recruitment and tissue necrosis [100]. IL 1, IL6 and IL8 have a bimodal and dynamic behavior. Fibroblast in healthy tissue secrete basal level of IL6 and IL8 that act to maintain tissue homeostasis [101]. IL6 participates in the recruitment and polarization of macrophages, natural killer cells and T cells, promoting immune control of cancer cells [4, 102]. By contrast, high level of IL6 and IL8 favor macrophage immunosopressive phenotype [103]. Augmented expression of IL6 in the peritumoural skin seems to be related to chronic UVexposure rather than to the presence of neoplastic cells, since IL6 is almost absent within BCC [20]. IL-1a in combination with EGFR inhibitor can induce a T cell-dependent anti-tumor immune response in head and neck squamous cell carcinoma [104]. Acute inflammation, mainly extensive production of IL1b by CAFs significantly contributes to the efficacy of photodynamic therapy in cutaneous SCC [105]. Thus, inflammation may not always be 'adverse' in the context of cancer and the balance of individual members of the cytokine network can also contribute to therapeutic response.

CAFs influence another major stromal component within tumors by directing tumor-associated macrophages (TAMs) polarization (M1, type I anti-tumor or M2, type II immunosuppressive phenotype) [106]. Even if this study does not evidence any predictive specific effect on macrophages polarization, an interesting patient-based study demonstrated that the antitumor effect of paclitaxel may occur in part via reactivation of the immune response against cancer, guiding tumor-associated macrophages toward the M1-like anti-tumor phenotype [107]. In line with our study, the effect on TAM indicates that paclitaxel-based antitumor therapy does not target only cancer cells but also heterotypic interactions. Moreover, in line with our data strong IL1b occurs also in Onco-P20 treated macrophages. The advantage is that targeting tumor cells and normal stromal cells with the same molecule could offer a more effective and durable response since normal cells appear to have a relatively stable genetic constitution in contrast to the genetically instable genomes of cancer cells.

\section{Conclusion}

Overall our experiments clearly demonstrated that CAF-cancer cells interaction, at least those mediated by secreted factors, could be re-direct by Onco-P20 onto a tumor suppressive function. The enhanced Onco-P20 up-take by fibroblasts compared to standard free paclitaxel also encourage the use of lower therapeutic active doses limiting the toxic effect of uninvolved cells.

\section{Abbreviations}

BBC: basal cell carcinoma

CAFs: Cancer associated fibroblasts

ECM: Extracellular matrix

EGF: Epidermal growth factor

FAP-a: Fibroblast activated protein-a

FGF: Fibroblast growth factor

FSP1: Fibroblast-specific protein-1

HA: Hyaluronic acid

HKGS: Human Keratinocytes Growth Supplement 
NHF: Normal human fibroblasts

NHK: Normal human keratinocytes

NMSC: Non-melanoma skin cancer

PDGF: Platelet-derived growth factor

PDGFR- $\alpha$ and $\beta$ : Platelet-derived growth factor receptor- $\alpha$ and $\beta$

PML promyelocytic leukemia protein

PTX: Paclitaxel

SCC: Squamous cell carcinoma

VEGF: Vascular endothelia growth factor,

Wnts: wingless-type MMTV integration site family members

a-SMA: a-smooth muscle actin

\section{Declarations}

Ethics approval: The Institutional Research Ethics Committee (Istituti Regina Elena e San Gallicano) approved all research activities involving human subjects. The Declaration of Helsinki Principles was followed and patients gave written informed consent to collect samples of human material for research.

Consent for publication: All authors have approved the manuscript and agree with its submission to Journal of Experimental \& Clinical Cancer Research.

Availability of data and materials: The datasets used or analysed during the current study are available from the corresponding author on reasonable request.

Disclosure of potential financial conflict of interests: All authors state no competing financial of interest.

Author Contributors: BB designed the study, conducted the experiments, analyzed data, and wrote the manuscript; MP contributed to the study design and critically revised the paper. SC, GL and VM performed part of the experiments. EM selected patients and collected tissue sample. All authors discussed the results and approved the final version of the manuscript.

Acknowledgements: We would like to thank the surgical team, Division of Plastic and Reconstructive Surgery, San Gallicano Dermatologic Institute for facilitating acquisition of tissue sample especially to Romina Settembrini for technical coordination.

Conflict of interest: This work has been supported by a grant from Fidia Farmaceutici, Abano Terme, Italy. The funding sources had no role in the study design, data collection, data analysis, data interpretation, and writing of this report or in the decision to submit the paper for publication.

\section{References}

1. Eisemann N, Waldmann A, Geller AC, Weinstock MA, Volkmer B, Greinert R, et al. Non-melanoma skin cancer incidence and impact of skin cancer screening on incidence. J Invest Dermatol. 2014;134:43-50.

2. Bizzarri M, Cucina A, Proietti S. Tumor Reversion: Mesenchymal-Epithelial Transition as a Critical Step in Managing the Tumor-Microenvironment CrossTalk. Curr Pharm Des. 2017;23:4705-15.

3. Ridge SM, Sullivan FJ, Glynn SA. Mesenchymal stem cells: key players in cancer progression. Mol Cancer. 2017;16:31,017-0597-8.

4. Kalluri R. The biology and function of fibroblasts in cancer. Nat Rev Cancer. 2016;16:582-98.

5. Rozario T, DeSimone DW. The extracellular matrix in development and morphogenesis: a dynamic view. Dev Biol. 2010;341:126-40.

6. Wickström SA, Radovanac K, Fässler R. Genetic analyses of integrin signaling. Cold Spring Harb Perspect Biol. 2011;3:a005116. doi: 10.1101/cshperspect.a005116.

7. Hanahan D, Weinberg RA. Hallmarks of cancer: the next generation. Cell. 2011;144:646-74.

8. Errarte P, Larrinaga G, López JI. The role of cancer-associated fibroblasts in renal cell carcinoma. An example of tumor modulation through tumor/nontumor cell interactions. J Adv Res. 2019;21:103-8.

9. Miyai Y, Esaki N, Takahashi M, Enomoto A. Cancer-associated fibroblasts that restrain cancer progression: Hypotheses and perspectives. Cancer Sci. 2020;111:1047-57.

10. Nurmik M, Ullmann P, Rodriguez F, Haan S, Letellier E. In search of definitions: Cancer-associated fibroblasts and their markers. Int $J$ Cancer. 2020;146:895-905.

11. Sahai E, Astsaturov I, Cukierman E, DeNardo DG, Egeblad M, Evans RM, et al. A framework for advancing our understanding of cancer-associated fibroblasts. Nat Rev Cancer. 2020;20:174-86. 
12. Tomasek JJ, Gabbiani G, Hinz B, Chaponnier C, Brown RA. Myofibroblasts and mechano-regulation of connective tissue remodelling. Nat Rev Mol Cell Biol. 2002;3:349-63.

13. Dvorak HF. Tumors: wounds that do not heal. Similarities between tumor stroma generation and wound healing. N Engl J Med. 1986;315:1650-9.

14. Liu D, Hornsby PJ. Senescent human fibroblasts increase the early growth of xenograft tumors via matrix metalloproteinase secretion. Cancer Res. 2007;67:3117-26.

15. Räsänen K, Vaheri A. Activation of fibroblasts in cancer stroma. Exp Cell Res. 2010;316:2713-22.

16. Gieniec KA, Butler LM, Worthley DL, Woods SL. Cancer-associated fibroblasts-heroes or villains?. Br J Cancer. 2019;121:293-302.

17. Flaberg E, Markasz L, Petranyi G, Stuber G, Dicso F, Alchihabi N, et al. High-throughput live-cell imaging reveals differential inhibition of tumor cell proliferation by human fibroblasts. Int J Cancer. 2011;128:2793-802.

18. Rhim AD, Oberstein PE, Thomas DH, Mirek ET, Palermo CF, Sastra SA, et al. Stromal elements act to restrain, rather than support, pancreatic ductal adenocarcinoma. Cancer Cell. 2014;25:735-47.

19. Özdemir BC, Pentcheva-Hoang T, Carstens JL, Zheng X, Wu CC, Simpson TR, et al. Depletion of carcinoma-associated fibroblasts and fibrosis induces immunosuppression and accelerates pancreas cancer with reduced survival. Cancer Cell. 2014;25:719-34.

20. Omland SH, Wettergren EE, Mollerup S, Asplund M, Mourier T, Hansen AJ, et al. Cancer associated fibroblasts (CAFs) are activated in cutaneous basal cell carcinoma and in the peritumoural skin. BMC Cancer. 2017;17:675,017-3663-0.

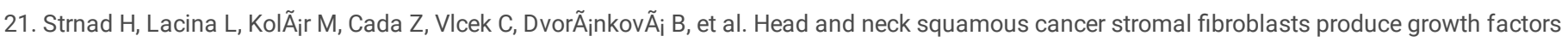
influencing phenotype of normal human keratinocytes. Histochem Cell Biol. 2010;133:201-11.

22. Ishii G, Ochiai A, Neri S. Phenotypic and functional heterogeneity of cancer-associated fibroblast within the tumor microenvironment. Adv Drug Deliv Rev. 2016;99:186-96.

23. Micke P, Kappert K, Ohshima M, Sundquist C, Scheidl S, Lindahl P, et al. In situ identification of genes regulated specifically in fibroblasts of human basal cell carcinoma. J Invest Dermatol. 2007;127:1516-23.

24. LeBleu VS, Kalluri R. A peek into cancer-associated fibroblasts: origins, functions and translational impact. Dis Model Mech. 2018;11:dmm029447. doi: 10.1242/dmm.029447.

25. Raz Y, Erez N. An inflammatory vicious cycle: Fibroblasts and immune cell recruitment in cancer. Exp Cell Res. 2013;319:1596-603.

26. Kanzaki R, Pietras K. Heterogeneity of cancer-associated fibroblasts: Opportunities for precision medicine. Cancer Sci. 2020.

27. Shalapour S, Karin M. Pas de Deux: Control of Anti-tumor Immunity by Cancer-Associated Inflammation. Immunity. 2019;51:15-26.

28. Qu X, Tang Y, Hua S. Immunological Approaches Towards Cancer and Inflammation: A Cross Talk. Front Immunol. 2018;9:563.

29. Erez N, Truitt M, Olson P, Arron ST, Hanahan D. Cancer-Associated Fibroblasts Are Activated in Incipient Neoplasia to Orchestrate Tumor-Promoting Inflammation in an NF-kappaB-Dependent Manner. Cancer Cell. 2010;17:135-47.

30. Leiter U, Eigentler T, Garbe C. Epidemiology of skin cancer. Adv Exp Med Biol. 2014;810:120-40.

31. Zhang D, Yang R, Wang S, Dong Z. Paclitaxel: new uses for an old drug. Drug Des Devel Ther. 2014;8:279-84.

32. Paolino D, Celia C, Trapasso E, Cilurzo F, Fresta M. Paclitaxel-loaded ethosomesÂ $\circledast$ : potential treatment of squamous cell carcinoma, a malignant transformation of actinic keratoses. Eur J Pharm Biopharm. 2012;81:102-12.

33. Singla AK, Garg A, Aggarwal D. Paclitaxel and its formulations. Int J Pharm. 2002;235:179-92.

34. Barceló R, Viteri A, Muñoz A, Gil-Negrete A, Rubio I, López-Vivanco G. Paclitaxel for progressive basal cell carcinoma. J Am Acad Dermatol. 2006;54:S50-2.

35. Platt VM, Szoka FC,Jr. Anticancer therapeutics: targeting macromolecules and nanocarriers to hyaluronan or CD44, a hyaluronan receptor. Mol Pharm. 2008;5:474-86.

36. Kinugasa Y, Matsui T, Takakura N. CD44 expressed on cancer-associated fibroblasts is a functional molecule supporting the stemness and drug resistance of malignant cancer cells in the tumor microenvironment. Stem Cells. 2014;32:145-56.

37. CoccÃ “ V, Vitale A, Colombo S, Bonomi A, Sisto F, Ciusani E, et al. Human skin-derived fibroblasts used as a 'Trojan horse' for drug delivery. Clin Exp Dermatol. 2016;41:417-24.

38. Rosato A, Banzato A, De Luca G, Renier D, Bettella F, Pagano C, et al. HYTAD1-p20: a new paclitaxel-hyaluronic acid hydrosoluble bioconjugate for treatment of superficial bladder cancer. Urol Oncol. 2006;24:207-15.

39. Karvinen S, Kosma VM, Tammi MI, Tammi R. Hyaluronan, CD44 and versican in epidermal keratinocyte tumours. Br J Dermatol. 2003;148:86-94.

40. Calvete J, Larrinaga G, Errarte P, MartÃn AM, Dotor A, Esquinas C, et al. The coexpression of fibroblast activation protein (FAP) and basal-type markers (CK 5/6 and CD44) predicts prognosis in high-grade invasive urothelial carcinoma of the bladder. Hum Pathol. 2019;91:61-8.

41. Morath I, Hartmann TN, Orian-Rousseau V. CD44: More than a mere stem cell marker. Int J Biochem Cell Biol. 2016;81:166-73.

42. Thapa R, Wilson GD. The Importance of CD44 as a Stem Cell Biomarker and Therapeutic Target in Cancer. Stem Cells Int. 2016;2016:2087204.

43. Blagosklonny MV. Cell cycle arrest is not senescence. Aging (Albany NY). 2011;3:94-101.

44. Bernardi R, Pandolfi PP. Structure, dynamics and functions of promyelocytic leukaemia nuclear bodies. Nat Rev Mol Cell Biol. 2007;8:1006-16.

45. Wong H, Riabowol K. Differential CDK-inhibitor gene expression in aging human diploid fibroblasts. Exp Gerontol. 1996;31:311-25.

46. Burton DG, Sheerin AN, Ostler EL, Smith K, Giles PJ, Lowe J, et al. Cyclin D1 overexpression permits the reproducible detection of senescent human vascular smooth muscle cells. Ann N Y Acad Sci. 2007;1119:20-31.

Page 9/20 
47. Foijer F, Simonis M, van Vliet M, Wessels L, Kerkhoven R, Sorger PK, et al. Oncogenic pathways impinging on the G2-restriction point. Oncogene. 2008;27:1142-54.

48. Toettcher JE, Loewer A, Ostheimer GJ, Yaffe MB, Tidor B, Lahav G. Distinct mechanisms act in concert to mediate cell cycle arrest. Proc Natl Acad Sci U S A. 2009;106:785-90.

49. Cebulla CM, Jockovich ME, Piña Y, Boutrid H, Alegret A, Kulak A, et al. Basic fibroblast growth factor impact on retinoblastoma progression and survival. Invest Ophthalmol Vis Sci. 2008;49:5215-21.

50. Root LL, Shipley GD. Human dermal fibroblasts express multiple bFGF and aFGF proteins. In Vitro Cell Dev Biol. 1991;27A:815-22.

51. Bhowmick NA, Chytil A, Plieth D, Gorska AE, Dumont N, Shappell S, et al. TGF-beta signaling in fibroblasts modulates the oncogenic potential of adjacent epithelia. Science. 2004;303:848-51.

52. Pilarsky C, Ammerpohl O, Sipos B, Dahl E, Hartmann A, Wellmann A, et al. Activation of Wnt signalling in stroma from pancreatic cancer identified by gene expression profiling. J Cell Mol Med. 2008;12:2823-35.

53. Zhang W, Borcherding N, Kolb R. IL-1 Signaling in Tumor Microenvironment. Adv Exp Med Biol. 2020;1240:1-23.

54. Pedrero JM, Carracedo DG, Pinto CM, Zapatero AH, Rodrigo JP, Nieto CS, et al. Frequent genetic and biochemical alterations of the PI 3-K/AKT/PTEN pathway in head and neck squamous cell carcinoma. Int J Cancer. 2005;114:242-8.

55. Geary LA, Nash KA, Adisetiyo H, Liang M, Liao CP, Jeong JH, et al. CAF-secreted annexin A1 induces prostate cancer cells to gain stem cell-like features. Mol Cancer Res. 2014;12:607-21.

56. Jose PJ, Griffiths-Johnson DA, Collins PD, Walsh DT, Moqbel R, Totty NF, et al. Eotaxin: a potent eosinophil chemoattractant cytokine detected in a guinea pig model of allergic airways inflammation. J Exp Med. 1994;179:881-7.

57. Yeh CR, Hsu I, Song W, Chang H, Miyamoto H, Xiao GQ, et al. Fibroblast ERÎt promotes bladder cancer invasion via increasing the CCL1 and IL-6 signals in the tumor microenvironment. Am J Cancer Res. 2015;5:1146-57.

58. McGillis ST, Fein H. Topical treatment strategies for non-melanoma skin cancer and precursor lesions. Semin Cutan Med Surg. 2004;23:174-83.

59. Kalluri R, Zeisberg M. Fibroblasts in cancer. Nat Rev Cancer. 2006;6:392-401.

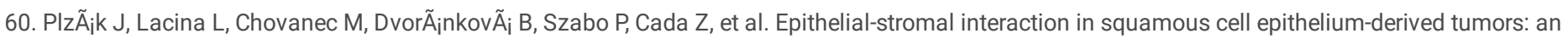
important new player in the control of tumor biological properties. Anticancer Res. 2010;30:455-62.

61. Ziani L, Chouaib S, Thiery J. Alteration of the Antitumor Immune Response by Cancer-Associated Fibroblasts. Front Immunol. 2018;9:414.

62. Lambrechts D, Wauters E, Boeckx B, Aibar S, Nittner D, Burton O, et al. Phenotype molding of stromal cells in the lung tumor microenvironment. Nat Med. 2018;24:1277-89.

63. Banzato A, Bobisse S, Rondina M, Renier D, Bettella F, Esposito G, et al. A paclitaxel-hyaluronan bioconjugate targeting ovarian cancer affords a potent in vivo therapeutic activity. Clin Cancer Res. 2008;14:3598-606.

64. Montagner IM, Banzato A, Zuccolotto G, Renier D, Campisi M, Bassi P, et al. Paclitaxel-hyaluronan hydrosoluble bioconjugate: mechanism of action in human bladder cancer cell lines. Urol Oncol. 2013;31:1261-9.

65. Bassi PF, Volpe A, D'Agostino D, Palermo G, Renier D, Franchini S, et al. Paclitaxel-hyaluronic acid for intravesical therapy of bacillus Calmette-GuÃ $\odot$ rin refractory carcinoma in situ of the bladder: results of a phase I study. J Urol. 2011;185:445-9.

66. Barkat MA, Beg S, Pottoo FH, Ahmad FJ. Nanopaclitaxel therapy: an evidence based review on the battle for next-generation formulation challenges. Nanomedicine (Lond). 2019;14:1323-41.

67. Duchi S, Dambruoso P, Martella E, Sotgiu G, Guerrini A, Lucarelli E, et al. Thiophene-based compounds as fluorescent tags to study mesenchymal stem cell uptake and release of taxanes. Bioconjug Chem. 2014;25:649-55.

68. Straubinger RM, Balasubramanian SV. Preparation and characterization of taxane-containing liposomes. Methods Enzymol. 2005;391:97-117.

69. Blagosklonny MV, Darzynkiewicz Z, Halicka HD, Pozarowski P, Demidenko ZN, Barry JJ, et al. Paclitaxel induces primary and postmitotic G1 arrest in human arterial smooth muscle cells. Cell Cycle. 2004;3:1050-6.

70. Carvajal D, Tovar C, Yang H, Vu BT, Heimbrook DC, Vassilev LT. Activation of p53 by MDM2 antagonists can protect proliferating cells from mitotic inhibitors. Cancer Res. 2005;65:1918-24.

71. Wahl AF, Donaldson KL, Fairchild C, Lee FY, Foster SA, Demers GW, et al. Loss of normal p53 function confers sensitization to Taxol by increasing G2/M arrest and apoptosis. Nat Med. 1996;2:72-9.

72. Lanni JS, Lowe SW, Licitra EJ, Liu JO, Jacks T. P53-Independent Apoptosis Induced by Paclitaxel through an Indirect Mechanism. Proc Natl Acad Sci U S A. 1997;94:9679-83.

73. Bosco DB, Kenworthy R, Zorio DA, Sang QX. Human mesenchymal stem cells are resistant to Paclitaxel by adopting a non-proliferative fibroblastic state. PLoS One. 2015;10:e0128511.

74. Bonomi A, Ghezzi E, Pascucci L, Aralla M, Ceserani V, Pettinari L, et al. Effect of canine mesenchymal stromal cells loaded with paclitaxel on growth of canine glioma and human glioblastoma cell lines. Vet J. 2017;223:41-7.

75. Coccè V, Franzè S, Brini AT, Giannì AB, Pascucci L, Ciusani E, et al. In Vitro Anticancer Activity of Extracellular Vesicles (EVs) Secreted by Gingival Mesenchymal Stromal Cells Primed with Paclitaxel. Pharmaceutics. 2019;11:61. doi: 10.3390/pharmaceutics11020061.

76. Nilforoushzadeh MA, Zare M, Zarrintaj P, Alizadeh E, Taghiabadi E, Heidari-Kharaji M, et al. Engineering the niche for hair regeneration - A critical review. Nanomedicine. 2019;15:70-85. 
77. Quan T, Fisher GJ. Role of Age-Associated Alterations of the Dermal Extracellular Matrix Microenvironment in Human Skin Aging: A Mini-Review. Gerontology. 2015;61:427-34.

78. Larsson LG. Oncogene- and tumor suppressor gene-mediated suppression of cellular senescence. Semin Cancer Biol. 2011;21:367-76.

79. Collado M, Serrano M. Senescence in tumours: evidence from mice and humans. Nat Rev Cancer. 2010;10:51-7.

80. Velarde MC, Demaria M, Campisi J. Senescent cells and their secretory phenotype as targets for cancer therapy. Interdiscip Top Gerontol. 2013;38:17-27.

81. Pitiyage GN, Slijepcevic P, Gabrani A, Chianea YG, Lim KP, Prime SS, et al. Senescent mesenchymal cells accumulate in human fibrosis by a telomereindependent mechanism and ameliorate fibrosis through matrix metalloproteinases. J Pathol. 2011;223:604-17.

82. TIsty TD, Hein PW. Know thy neighbor: stromal cells can contribute oncogenic signals. Curr Opin Genet Dev. 2001;11:54-9.

83. Bechtel W, McGoohan S, Zeisberg EM, MÃ̄1/4ller GA, Kalbacher H, Salant DJ, et al. Methylation determines fibroblast activation and fibrogenesis in the kidney. Nat Med. 2010;16:544-50.

84. Peng Q, Zhao L, Hou Y, Sun Y, Wang L, Luo H, et al. Biological characteristics and genetic heterogeneity between carcinoma-associated fibroblasts and their paired normal fibroblasts in human breast cancer. PLoS One. 2013;8:e60321.

85. Moschos SJ, Mantzoros CS. The role of the IGF system in cancer: from basic to clinical studies and clinical applications. Oncology. 2002;63:317-32.

86. Grugan KD, Miller CG, Yao Y, Michaylira CZ, Ohashi S, Klein-Szanto AJ, et al. Fibroblast-secreted hepatocyte growth factor plays a functional role in esophageal squamous cell carcinoma invasion. Proc Natl Acad Sci U S A. 2010;107:11026-31.

87. Matsumoto K, Nakamura T. Hepatocyte growth factor and the Met system as a mediator of tumor-stromal interactions. Int J Cancer. 2006;119:477-83.

88. Huang TX, Guan XY, Fu L. Therapeutic targeting of the crosstalk between cancer-associated fibroblasts and cancer stem cells. Am J Cancer Res. 2019;9:1889-904.

89. Ferber A, Chang C, Sell C, Ptasznik A, Cristofalo VJ, Hubbard K, et al. Failure of senescent human fibroblasts to express the insulin-like growth factor-1 gene. J Biol Chem. 1993;268:17883-8.

90. Lewis DA, Travers JB, Somani AK, Spandau DF. The IGF-1/IGF-1R signaling axis in the skin: a new role for the dermis in aging-associated skin cancer. Oncogene. 2010;29:1475-85.

91. Valcz G, Sipos F, Tulassay Z, Molnar B, Yagi Y. Importance of carcinoma-associated fibroblast-derived proteins in clinical oncology. J Clin Pathol. 2014;67:1026-31.

92. Andreadis ST, Hamoen KE, Yarmush ML, Morgan JR. Keratinocyte growth factor induces hyperproliferation and delays differentiation in a skin equivalent model system. FASEB J. 2001;15:898-906.

93. Guo L, Yu QC, Fuchs E. Targeting expression of keratinocyte growth factor to keratinocytes elicits striking changes in epithelial differentiation in transgenic mice. EMBO J. 1993;12:973-86.

94. Hines MD, Allen-Hoffmann BL. Keratinocyte growth factor inhibits cross-linked envelope formation and nucleosomal fragmentation in cultured human keratinocytes. J Biol Chem. 1996;271:6245-51.

95. Miyashita T, Tajima H, Makino I, Okazaki M, Yamaguchi T, Ohbatake Y, et al. Neoadjuvant Chemotherapy with Gemcitabine Plus Nab-paclitaxel Reduces the Number of Cancer-associated Fibroblasts Through Depletion of Pancreatic Stroma. Anticancer Res. 2018;38:337-43.

96. Sobel K, Tham M, Stark HJ, Stammer H, PrÃ.atzel-Wunder S, Bickenbach JR, et al. Wnt-3a-activated human fibroblasts promote human keratinocyte proliferation and matrix destruction. Int J Cancer. 2015;136:2786-98.

97. Blagosklonny MV. Cell senescence and hypermitogenic arrest. EMBO Rep. 2003;4:358-62.

98. Silzle T, Kreutz M, Dobler MA, Brockhoff G, Knuechel R, Kunz-Schughart LA. Tumor-associated fibroblasts recruit blood monocytes into tumor tissue. Eur J Immunol. 2003;33:1311-20.

99. Silzle T, Randolph GJ, Kreutz M, Kunz-Schughart LA. The fibroblast: sentinel cell and local immune modulator in tumor tissue. Int J Cancer. 2004;108:17380.

100. Cheng SS, Lukacs NW, Kunkel SL. Eotaxin/CCL11 suppresses IL-8/CXCL8 secretion from human dermal microvascular endothelial cells. J Immunol. 2002;168:2887-94.

101. Noske K. Secreted immunoregulatory proteins in the skin. J Dermatol Sci. 2018;89:3-10.

102. Harper J, Sainson RC. Regulation of the anti-tumour immune response by cancer-associated fibroblasts. Semin Cancer Biol. 2014;25:69-77.

103. Nagarsheth N, Wicha MS, Zou W. Chemokines in the cancer microenvironment and their relevance in cancer immunotherapy. Nat Rev Immunol. 2017;17:559-72.

104. Espinosa-Cotton M, Rodman lii SN, Ross KA, Jensen IJ, Sangodeyi-Miller K, McLaren AJ, et al. Interleukin-1 alpha increases anti-tumor efficacy of cetuximab in head and neck squamous cell carcinoma. J Immunother Cancer. 2019;7:79,019-0550-z.

105. Nie S, Wang X, Wang H. NLRP3 Inflammasome Mediated Interleukin-1 $\hat{I}^{2}$ Production in Cancer-Associated Fibroblast Contributes to ALA-PDT for Cutaneous Squamous Cell Carcinoma. Cancer Manag Res. 2019;11:10257-67.

106. Laplagne C, Domagala M, Le Naour A, Quemerais C, Hamel D, FourniÃ@ JJ, et al. Latest Advances in Targeting the Tumor Microenvironment for Tumor Suppression. Int J Mol Sci. 2019;20:4719. doi: 10.3390/ijms20194719.

107. Wanderley CW, Colón DF, Luiz JPM, Oliveira FF, Viacava PR, Leite CA, et al. Paclitaxel Reduces Tumor Growth by Reprogramming Tumor-Associated Macrophages to an M1 Profile in a TLR4-Dependent Manner. Cancer Res. 2018;78:5891-900.

\section{Tables}

Page $11 / 20$ 
Table 1. Gene expression analysis of growth factors and CAF's markers in Onco-P20-treated fibroblasts after 2 weeks of continuous treatment. Data represent $\mathrm{X}$-fold increase or decrease respect to untreated cells. Results are mean $\pm S D$ of seven different experiments performed with fibroblasts isolated from independent donors. ${ }^{*} p<0.05$ and ${ }^{* *} p<0.001$.

\begin{tabular}{|c|c|}
\hline mRNA & $\begin{array}{c}\text { Onco-P20 } \\
\text { ( } \mathrm{x} \text {-fold change) }\end{array}$ \\
\hline HGF & $0.44 \pm 0.36^{* *}$ \\
\hline IGF & $0.72 \pm 0.97$ \\
\hline bFGF & $1.21 \pm 0.51$ \\
\hline KGF & $1.41 \pm 1.82$ \\
\hline EGF & $0.66 \pm 0.53$ \\
\hline VEGF & $0.692 \pm 0.29$ \\
\hline IGFBP3 & $2.06 \pm 2.05 * *$ \\
\hline IGFBP4 & $2.48 \pm 0.59^{*}$ \\
\hline IGFBPS & $2.14 \pm 1.9^{*}$ \\
\hline IGFBP6 & $2.1 \pm 0.54^{*}$ \\
\hline IGFBP7 & $1.62 \pm 0.68^{*}$ \\
\hline Wnt5a & $2.48 \pm 2.77^{*}$ \\
\hline DKK1 & $4.22 \pm 2.38^{* *}$ \\
\hline SFRP2 & $7.60 \pm 7.51^{*}$ \\
\hline TGF $\beta$ & $0.87 \pm 0.24$ \\
\hline PDGF $\alpha$ & $0.69 \pm 0.71$ \\
\hline PDGF $\beta$ & $0.57 \pm 0.25 * *$ \\
\hline$\alpha \mathrm{SMA}$ & $1.14 \pm 0.66$ \\
\hline FAP1 & $4.06 \pm 5.67^{*}$ \\
\hline$\| 1 \alpha$ & $18.6 \pm 15.9^{* *}$ \\
\hline$\| 1 \beta$ & $34.6 \pm 43.8 * *$ \\
\hline IL6 & $5.84 \pm 7.2^{*}$ \\
\hline 118 & $109.2 \pm 105.0^{*}$ \\
\hline
\end{tabular}

Table 2. Results of human inflammation genes array after 2 weeks treatment with Onco-P20 (or not ctrl cells). Results are mean \pm SD of seven different experiments performed with fibroblasts isolated from independent donors. ${ }^{*} p<0.05$ and ${ }^{* *} p<0.001$. Not detected (ND) 


\begin{tabular}{|c|c|c|c|c|c|c|c|c|}
\hline mRNA & $\mathrm{ctrl}$ & Onco-p20 & mRNA & cort & Onco-p20 & mRNA & $\mathrm{cut}$ & Onco-p20 \\
\hline A2M & $2.16 \pm 4.53$ & $12.6 \pm 9.97$ & 112RA & ND & ND & PLAZG2A & ND & ND \\
\hline ADRB1 & ND & ND & 112RB & ND & ND & PLA2G28 & ND & ND \\
\hline ADRB2 & $1.78 \pm 3.07$ & $3.87 \pm 7.09 * *$ & $112 \mathrm{RG}$ & No & ND & PLAZG2D & ND & ND \\
\hline ALOX12 & ND & ND & ITGAL & ND & ND & PLAZGAC & $0.19 \pm 0.15$ & $2.63 \pm 1.94^{*}$ \\
\hline ALOXS & ND & ND & IIGAM & ND & ND & PLAZGS & ND & ND \\
\hline$A N \times A_{1}$ & $1.70 \pm 0.33$ & $3.33 \pm 1.06 * *$ & ITG81 & $1.68 \pm 0.29$ & $2.96 \pm 1.5$ & PLA2G7 & ND & ND \\
\hline$A N \times A 3$ & $3.56 \pm 2.07$ & $3.40 \pm 2.08$ & $\pi G B 2$ & $0.51 \pm 0.32$ & $2.7 \pm 1.74^{\circ}$ & PDEAD & $0.33 \pm 0.43$ & $4.50 \pm 4.3$ \\
\hline ANXAS & $1.56 \pm 0.31$ & $2.02 \pm 0.54$ & KLK1 & ND & ND & PICB2 & ND & ND \\
\hline $82 \mathrm{M}$ & $0.43 \pm 0.70$ & $1.89 \pm 1.21 *$ & KLK14 & $0.55 \pm 0.93$ & $6.08 \pm 2.31 *$ & PLCB3 & $0.77 \pm 0.21$ & $0.66 \pm 0.15$ \\
\hline BOKRB1 & $0.23 \pm 0.12$ & $7.65 \pm 6.20^{*}$ & KuK15 & NO & ND & PICB4 & $2.01 \pm 1.77$ & $1.23 \pm 0.79$ \\
\hline воКRB2 & $0.33 \pm 6.20$ & $6.06 \pm 5.31^{*}$ & KLK2 & ND & ND & PLCD1 & $1.19 \pm 0.54$ & $1.69 \pm 0.47$ \\
\hline CACN1C & $1.4 \pm 0.69$ & $1.7 \pm 1.48$ & KLK3 & ND & ND & PICE1 & $0.60 \pm 0.63$ & $0.36 \pm 0.35$ \\
\hline CACN2D1 & ND & ND & KLKB1 & ND & ND & PLCG1 & $7.26 \pm 2.47$ & $13.9 \pm 1.18$ \\
\hline CACNB2 & $1.07 \pm 2.01$ & $2.04 \pm 1.63$ & kNG1 & ND & ND & PLCG2 & $1.90 \pm 1.28$ & $2.99 \pm 2.04$ \\
\hline CACNBA & $1.63 \pm 2.95$ & $4.07 \pm 6.04$ & LTAAH & $1.21 \pm 0.25$ & $2.34 \pm 0.78^{*}$ & PTAFR & $0.15 \pm 0.34$ & $1.08+1.52$ \\
\hline CASP1 & $1.72+0.65$ & $4.84 \pm 0.60$ & LTBAR & $2.15 \pm 0.87$ & $2.82+1.68$ & PTGDR & $0.09 \pm 0.2$ & $8.30 \pm 6.32^{*}$ \\
\hline $\cos 40$ & $2.57 \pm 1.72$ & $9.96 \pm 4.45 * *$ & LTAR2 & $0.81 \pm 0.63$ & $1.94 \pm 1.55$ & PTGER2 & $0.60 \pm 0.41$ & 4.06 44.27 \\
\hline $\cos 4016$ & ND & ND & LTCAS & $0.53 \pm 0.37$ & $0.53 \pm 0.28$ & PTGER3 & $2.5 \pm 2.65$ & $5.2 \pm 2.97$ \\
\hline CES1 & $0.27 \pm 0,19$ & $0.89 \div 0.9$ & MAPK1 & $0.63 \pm 0.48$ & $0.62 \pm 0.38$ & PTGFR & $1.0 \pm 0.41$ & $3.3 \pm 2.43$ \\
\hline CrsLtR1 & ND & $1.88 \pm 2.01$ & MAPK14 & $1.11 \pm 0.51$ & $1.95 \pm 1.01$ & PTGIR & $0.80 \pm 0.47$ & $1.55 \pm 0.54^{*}$ \\
\hline HPDG & ND & ND & MAPK 3 & $0.96 \pm 0.27$ & $1.40 \pm 0.47$ & PTGIS & $0.83 \pm 0.84$ & $2.57 \pm 2.47$ \\
\hline HRH1 & $2.91 \pm 0.99$ & $2.33 \pm 1.13$ & MAPKS & $1.33 \pm 0.71$ & $2.49 \pm 0.99$ & PTGS1 & $0.65 \pm 0.74$ & $1.1 \pm 0.50$ \\
\hline HRH2 & ND & ND & MC2R & ND & ND & PTOS2 & $0.42 \pm 0.49$ & $6.42 \pm 6.88$ \\
\hline HRH3 & ND & ND & NFKB1 & $0.28 \pm 0.15$ & $0.60 \pm 0.38$ & TBXA2R & $0.8 \pm 0.27$ & $1.7 \pm 0.78^{*}$ \\
\hline HTR3A & ND & ND & NOS2A & ND & ND & TBXAS1 & ND & ND \\
\hline HTR3B & ND & ND & $\mathrm{NR} 3 \mathrm{C} 1$ & $1.3 \pm 0.33$ & $1.9 \pm 0.86$ & TNF & ND & ND \\
\hline ICAM1 & $0.42 \pm 0.25$ & $9.57 \pm 6.17 *$ & PDEAA & $0.83 \pm 0.24$ & $1.03 \pm 0.21$ & TNFRSF1A & $1.4 \pm 0.52$ & $1.9 \pm 0.93$ \\
\hline "113 & ND & ND & PDEAB & $0.29 \pm 0.13$ & $2.59 \pm 2.75$ & TNFASF $1 \mathrm{~B}$ & $0.67 \pm 0.54$ & $2.48 \pm 1.07 * *$ \\
\hline IL1R1 & $0.98 \pm 0.66$ & $3.87 \pm 2.12^{*}$ & PDEAC & ND & ND & TNFRSF13B & $1.2 \pm 1.42$ & $12.8+9.62^{\circ}$ \\
\hline IL1R2 & ND & ND & PDEAD & $0.33 \pm 0.42$ & $4.50 \pm 4.30$ & veAM1 & $0.3 \pm 0.53$ & $13.2 \pm 21.6$ \\
\hline ILIRAPL2 & ND & ND & PLA2G10 & ND & ND & & & \\
\hline MLRL1 & ND & ND & PLA2G1B & ND & ND & & & \\
\hline
\end{tabular}

Table 3. Semi-quantitative analysis of multiple cytokines secreted by Onco-P20-treated fibroblastsafter 2 weeks of continuous treatment. Data represent $x$-fold increase or decrease respect to untreated cells. Results are mean \pm SD of four different experiments performed with fibroblasts isolated from independent donors. ${ }^{*} \mathrm{p}<0.05$ and ${ }^{* *} \mathrm{p}<0.001$.

\begin{tabular}{|lc}
\hline Target & $\begin{array}{c}\text { Onco-P20 } \\
\text { (x-fold change) }\end{array}$ \\
\hline CCL11 & $2.65 \pm 1.0^{*}$ \\
\hline CCL24 & $1.16 \pm 0.87$ \\
\hline GCSF & $0.57 \pm 0.34$ \\
\hline GMCSF & $1.03 \pm 0.44$ \\
\hline ING & $1.44 \pm 0.61$ \\
\hline IL1 $\alpha$ & $1.55 \pm 1.09$ \\
\hline IL13 & $2.11 \pm 1.58$ \\
\hline IL2 & $1.35 \pm 0.60$ \\
\hline IL3 & $1.03 \pm 0.59$ \\
\hline IL4 & $2.37 \pm 2.12$ \\
\hline IL6 & $8.65 \pm 4.84^{*}$ \\
\hline IL7 & $0.85 \pm 0.61$ \\
\hline IL8 & $4.40 \pm 1.64 *^{* *}$ \\
\hline IL10 & $1.22 \pm 0.61$ \\
\hline IL11 & $0.90 \pm 0.43$ \\
\hline IL12p40 & $0.96 \pm 0.71$ \\
\hline IL12p70 & $2.19 \pm 2.20$ \\
\hline IL13 & $0.73 \pm 0.57$ \\
\hline CCL1 & $0.26 \pm 0.31^{*}$ \\
\hline TIMP-2 & $0.81 \pm 0.2$ \\
\hline
\end{tabular}

\section{Figures}


Fig. 1

a

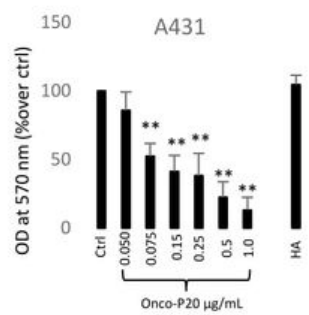

e

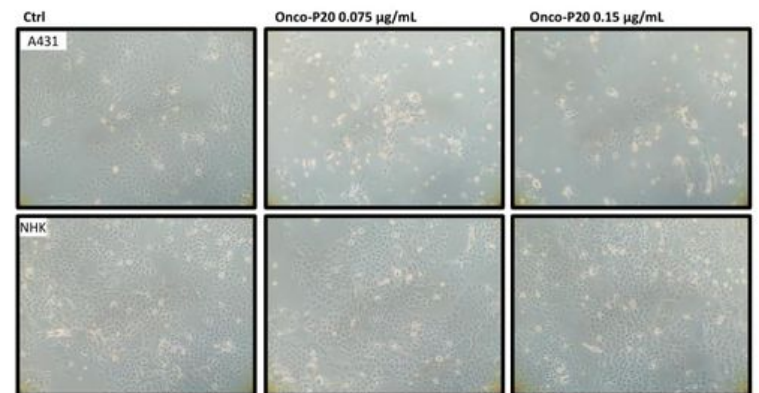

g

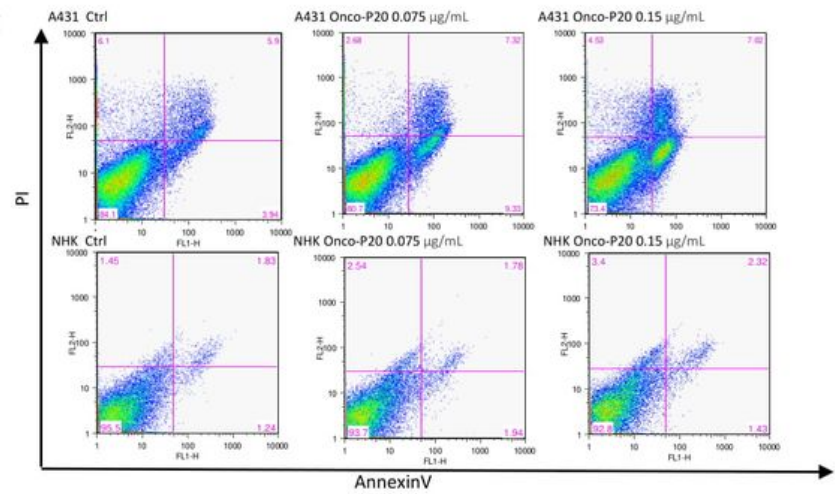

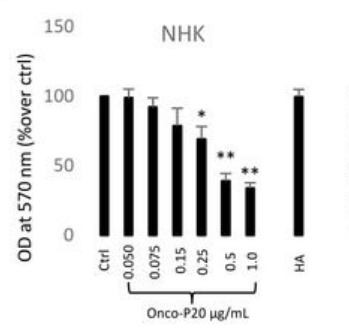

f d

150 NHK

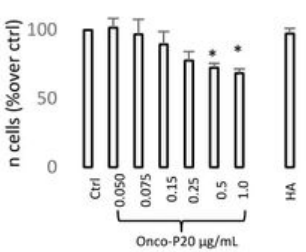

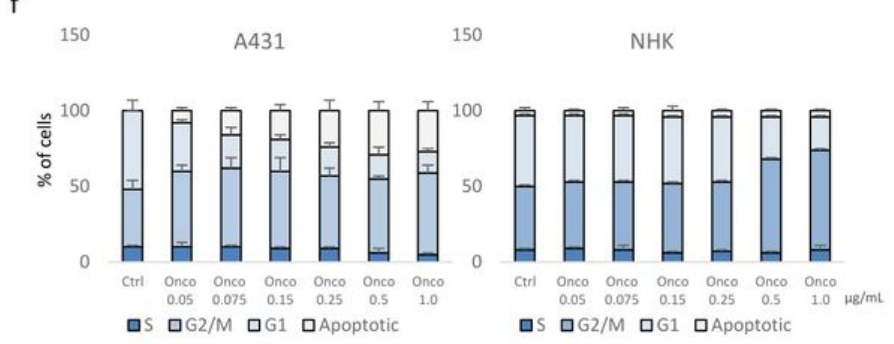

as $\square \mathrm{G} 2 / \mathrm{M}$ 口G1 DApoptotic

口S 口G2/M םG1 口Apoptotic

\section{Figure 1}

MTT assay (a) and cell count (b) of A431 cells treated (72h) with increasing concentration of Onco-P20 (range $0.05-1.0 \square \mathrm{g} / \mathrm{mL}$ ) or HA $1.0 \square \mathrm{g} / \mathrm{mL}$ equivalent to the HA concentration at the Onco-P20 higher doses. Data represent the mean \pm SD of three independent experiments were performed in duplicate. MTT assay (c) and cell count (d) of NHKs treated (72h) with increasing concentration of Onco-P20. Histograms represent the mean \pm SD of three NHK cell lines isolated from different donors. (e) Microscopic images of normal and carcinoma cells after 72h treatment with Onco-P20. (f) Cell cycle distribution of Onco-P20treated of normal and carcinoma cells. (g) Apoptosis was evaluated by FACS analysis using annexin V/iodide propidium staining. Dot plots show one representative experiment performed $24 \mathrm{~h}$ after Onco-P20 treatment. Statistical significance versus untreated control is reported as ${ }^{*} \mathrm{p}<0.05$ and $* \star \mathrm{p}<0.001$. 
Fig. 2

a

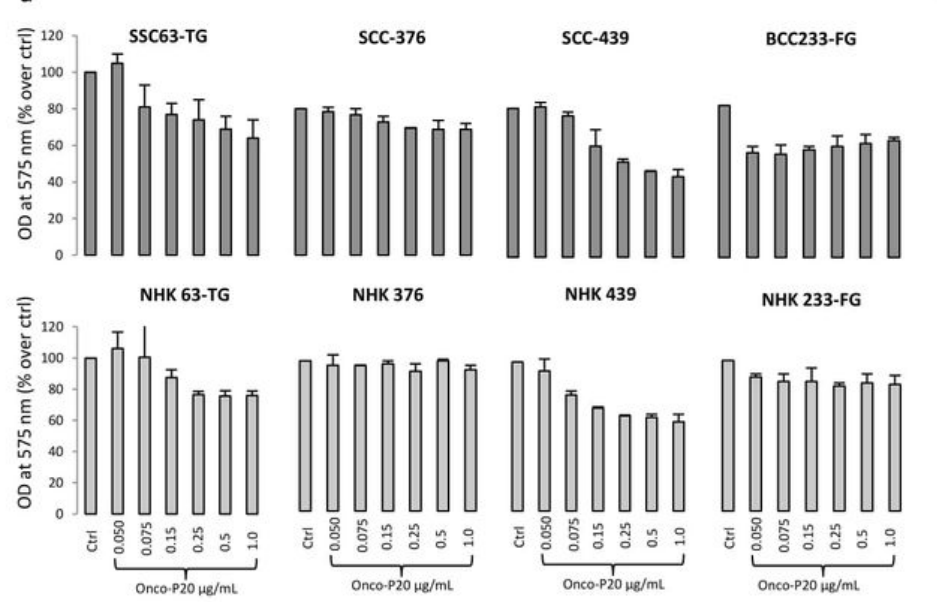

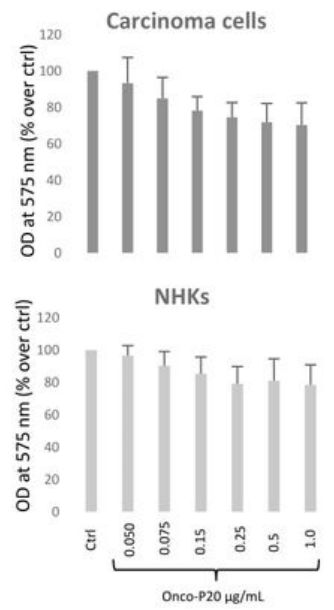

C

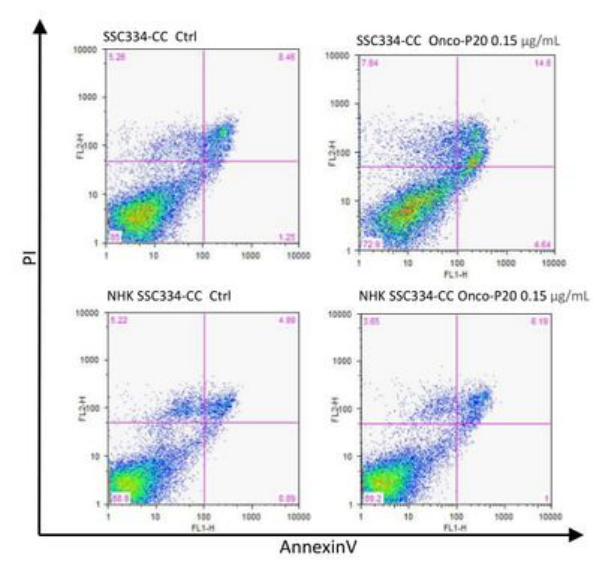

Figure 2

(a) MTT assay of several different NMSC cell lines and patient-matched NHKs after $72 \mathrm{~h}$ treatment with Onco-P20 (range 0.05-1.0 घg/mL). (b) Data are also reported as mean value $\pm \mathrm{SD}$. Experiments were performed in duplicate. (c) Annexin V/iodide propidium staining evidenced apoptosis cell death only in carcinoma cells. Dot plots show one representative experiment performed $24 \mathrm{~h}$ after Onco-P20 treatment. 
Fig. 3

a

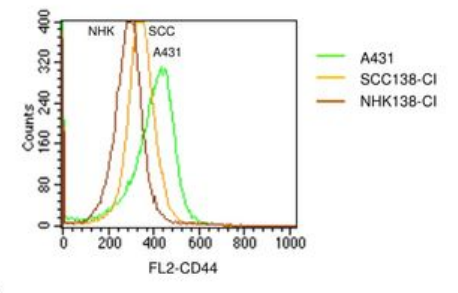

b

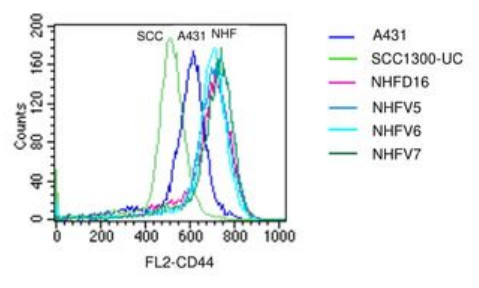

\section{Figure 3}

(a) One representative immunostaining of plasma membrane CD44 expression. Data demonstrated lower intensity in fresh isolated carcinoma cells (SCC138$\mathrm{Cl}$ ) compared to A431 carcinoma cell line. NHKs isolated from healthy skin of the same patient (NHK138-Cl) presented the lowest quantity of CD44. Histogram plot reports fluorescent intensity. (b) Similar to (a) semi-quantitative analysis of CD44 staining showed high expression in all NHF cell culture analyzed compared to A431 and in fresh isolated carcinoma cells (SCC1300-UC). 
Fig. 4

a

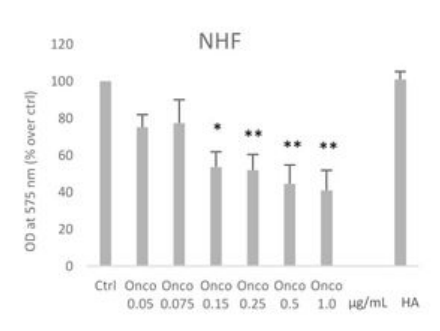

b
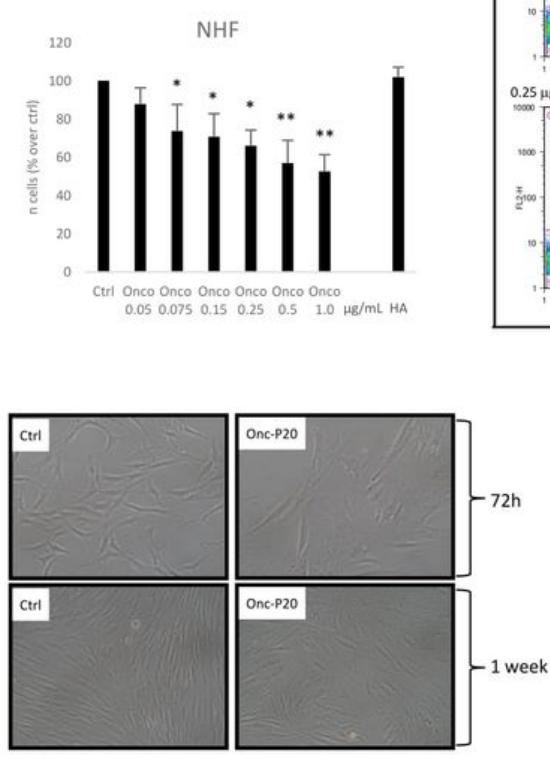

c

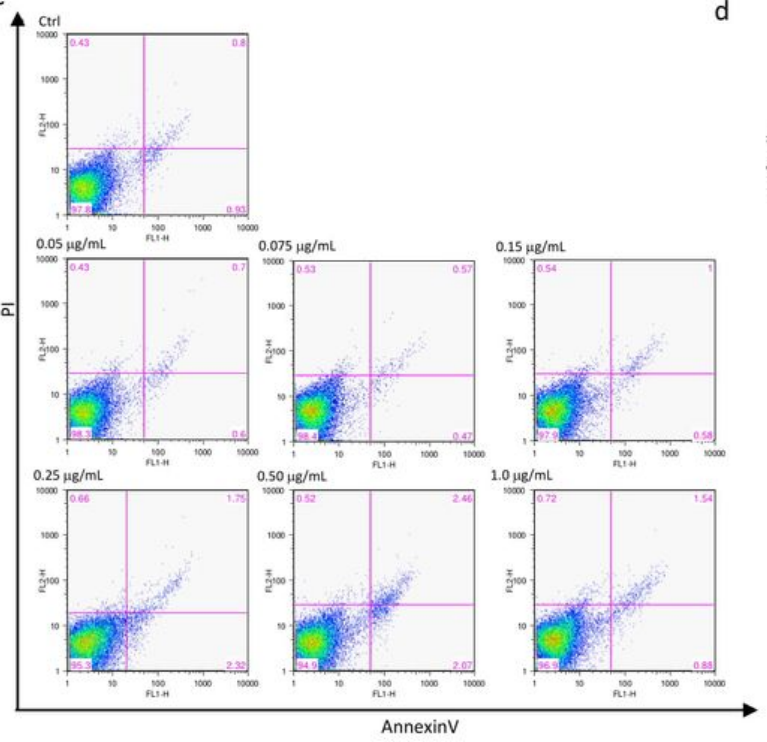

d

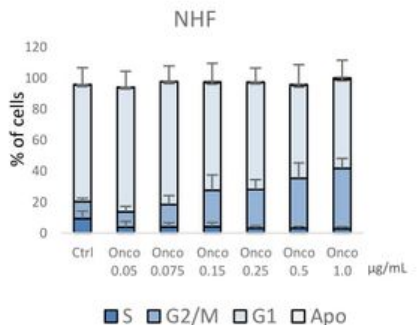

口S QG2/M QG1 QApo

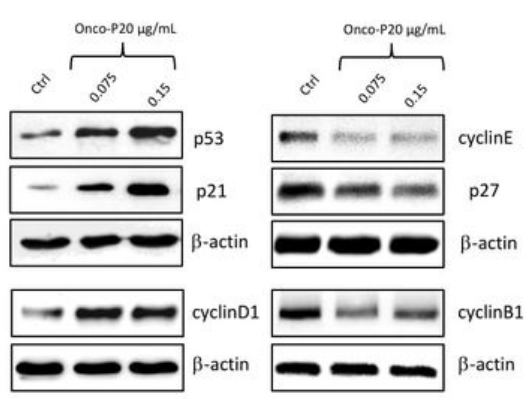

g

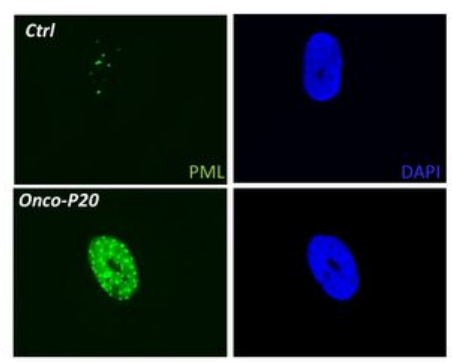

Figure 4

(a) MTT assay and cell count (b) of several different NHF cell lines treated (72h) with increasing concentration of Onco-P20 (range 0.05-1.0 $\mathrm{gg} / \mathrm{mL}$ ) or HA 1.0 $\square \mathrm{g} / \mathrm{mL}$ equivalent to the HA concentration at the Onco-P20 higher doses. (c) FACS analysis using annexin V/iodide propidium staining excluded apoptosis. Dot plots show one representative experiment performed $24 \mathrm{~h}$ after Onco-P20 treatment. Statistical significance versus untreated control is reported as * $<0.05$ and ${ }^{*} \mathrm{p}<0.001$. 
Fig. 5

a

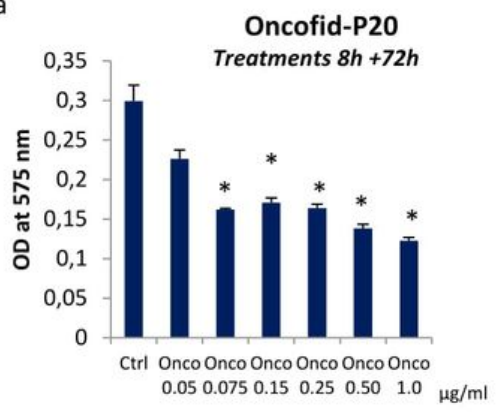

b

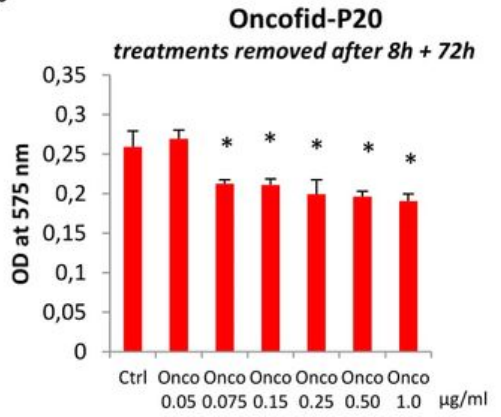

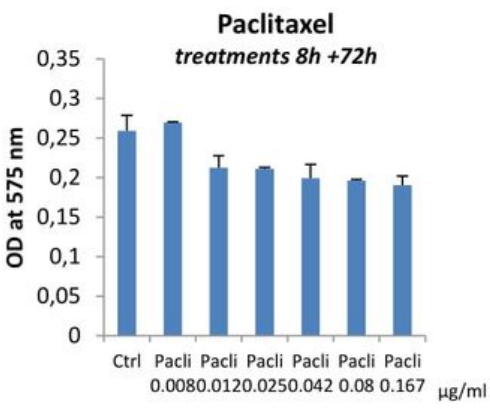

Paclitaxel

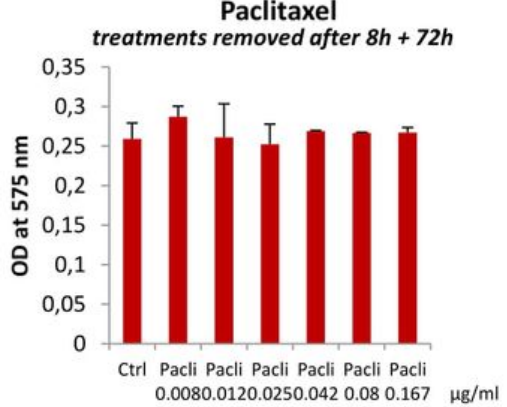

Figure 5

MTT assay of NHFs treated for $8 \mathrm{~h}$ with Onco-P20 or PTX before drug wash out (a) or treated continuously for $72 \mathrm{~h}$ with identical treatments (b). Data represent the mean \pm SD of three independent experiments were performed in duplicate. Statistical significance expressing Onco-P20 versus PTX-treated cells is reported as ${ }^{*} \mathrm{p}<0.05$. 
Fig. 6

a

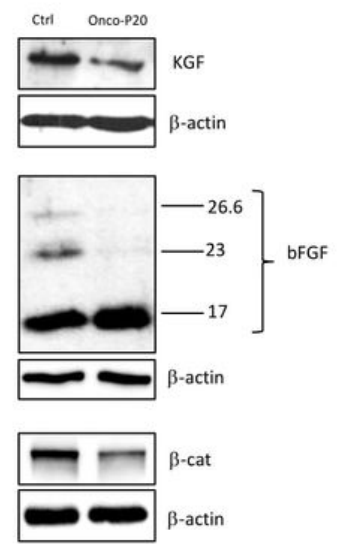

b

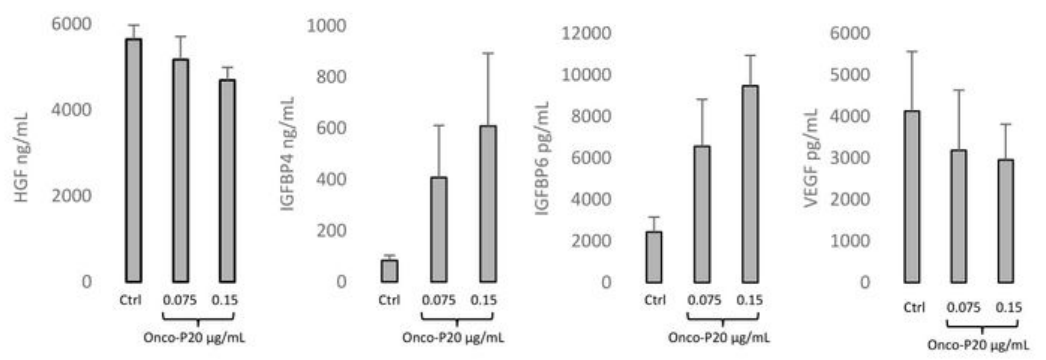

\section{Figure 6}

(a) One representative western blot analysis demonstrating the reduction of growth factors and $\triangle$-catenin expression in Onco-P20-treated (0.15 $\square \mathrm{g} / \mathrm{mL}) \mathrm{NHFs}$. Protein were extracted after 2 weeks treatment. (b) Immunoenzymatic quantification of IGFBP4, IGFBP6 and VEGF released in cell culture medium. After 2 weeks treatment, cells were incubated for additional $48 \mathrm{~h}$ with DMEM without FBS before medium collection. Results were normalized against protein concentration. 
Fig. 7

a

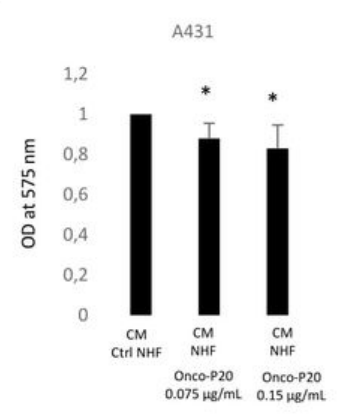

b
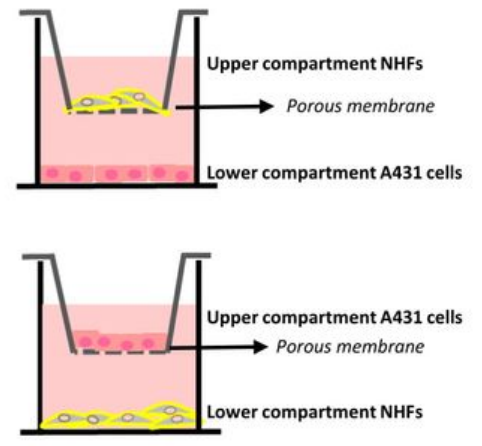

$4 \quad$ A431 lower

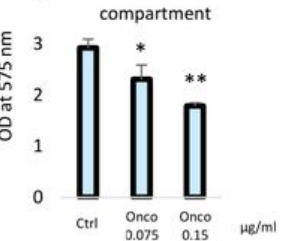

$4 \quad$ A431 higher

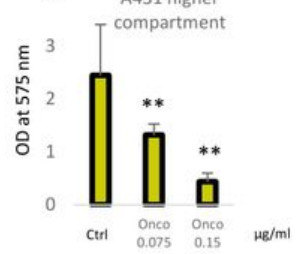

c

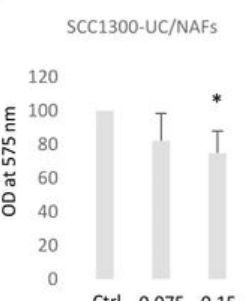

SCC1300-UC/CAFs Peril

$$
\begin{array}{r}
120 \\
100 \\
80 \\
60 \\
40 \\
20 \\
0
\end{array}
$$

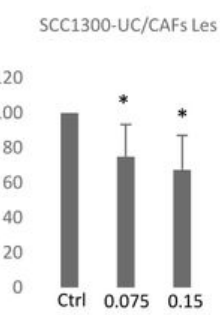

d

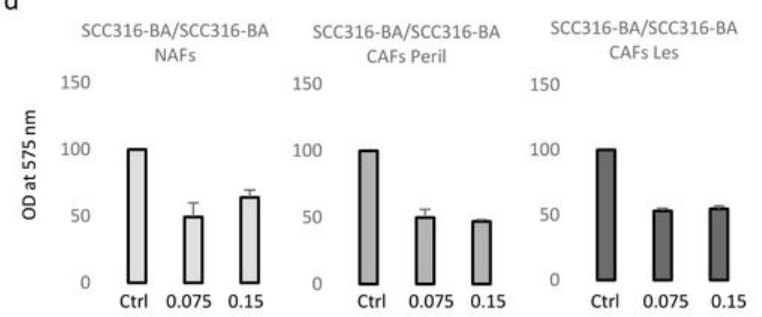

\section{Figure 7}

(a) MTT assay of A431 carcinoma cells grown in presence of CM collected from Onco-P20-treated fibroblast. After 2 weeks and an additional $48 \mathrm{~h}$ period without treatment, medium was replaced with M154 without supplements before CM harvesting. CM was diluted 1:5 in fresh M154. CM of untreated fibroblasts was used as control medium. Histograms represent mean \pm SD of three independent experiments performed with three different NHF cell lines at the experimental end point (72h). (b) Schematic representation of trans-well systems used for co-culture experiments. MTT assay after $72 \mathrm{~h}$ of A431 cells in coculture demonstrated dose-dependent anti-cancer activity of Onco-P20-treated normal fibroblasts. (c) MTT assay after $72 \mathrm{~h}$ of SCC1300-UC carcinoma cells in co-culture with fibroblasts isolated from uninvolved, perilesional and lesional area of carcinoma patients. Results report data relative three independent experiments performed with three different donors. (d) MTT assay after $72 \mathrm{~h}$ of SCC316-BA carcinoma cells in co-culture with matched fibroblasts isolated from uninvolved, perilesional and lesional of the same donor (SCC316-BA). Statistical significance versus untreated control cells is reported as * $<<0.05$ and ${ }^{* *} p<0.001$.

\section{Supplementary Files}

This is a list of supplementary files associated with this preprint. Click to download.

- supplmaterial.pdf 